\title{
La aplicación de la cláusula PPT del Plan de Acción beps en la red de convenios de doble imposición suscritos por Colombia
}

\section{The application of the beps Action Plan's ppt clause in the network of double taxation agreements signed by Colombia}

\section{A aplicação da cláusula PPT do Plano de Ação BEPs na rede de acordos de dupla tributação assinados pela Colômbia}

Jorge LEONARdo RodRÍGUEZ PiÑEROs* 


\title{
Resumen
}

En 2013, la OCDE inició el desarrollo del Plan de Acción BEPS, conformado por 15 acciones en las que se proponen medidas tendientes, entre otras cosas, a evitar el uso abusivo de los convenios de doble imposición, el cual concluyó con la suscripción de un Instrumento Multilateral que permite la modificación simultánea de los CDI suscritos por los Estados. Dentro de las medidas propuestas por la OCDE en el Plan de Acción BEPS para evitar el uso abusivo de los CDI se encuentra la de incluir en el convenio una cláusula general anti-abuso consistente en la aplicación del Test de Propósito Principal (PPT), que podría tener efectos directos en los contribuyentes, por lo que resulta pertinente y necesario analizar el alcance y aplicación de dicha cláusula en la red de CDI suscritos por Colombia, para, de esa manera, dar a los contribuyentes y a las administraciones una visión más clara de la figura.

Palabras clave: Planeación fiscal agresiva; Propósito principal; Tributación Internacional; BEPS; Instrumento Multilateral.

\begin{abstract}
In 2013 the OECD began the development of the BEPS Action Plan, consisting of 15 actions in which measures are proposed to, among other things, avoid the abusive use of Double Taxation Agreements, which concluded with the subscription of a Multilateral Agreement that allows the simultaneous modification of the DTA signed by the States. Among the measures proposed by the OECD in the BEPS Action plan to avoid de abusive use of the DTA is to include in the agreement a general anti-abuse clause consisting in the application of the Principal Purpose Test (PPT), which could have direct effects on taxpayers, so it is pertinent an necessary to analyze the scope and application od that clause in the network of DTA signed by Colombia so to give taxpayers and administrations a clearer vision of the figure.
\end{abstract}

Key Words: Aggressive Tax Planning; Main Purpose; International Taxation; BEPs; Multilateral Instrument.

\section{Resumo}

Em 2013, a OCDE iniciou o desenvolvimento do Plano de Ação BEPS, composto por 15 ações nas quais são propostas medidas, entre outras coisas, para impedir o uso abusivo de acordos de dupla tributação, concluídos com a assinatura de um Instrumento. Multilateral que permite a modificação simultânea dos CDIs assinados pelos Estados. Entre as medidas propostas pela OCDE no Plano de Ação do BEPS para impedir o uso abusivo de UDIs, está a inclusão de uma cláusula geral de combate ao abuso no acordo que consiste na aplicação do Teste de Propósito Principal (PPT), cuja aplicação poderia têm efeitos diretos sobre os contribuintes, por isso é pertinente e necessário analisar o escopo e a aplicação da referida cláusula na rede CDI assinada pela Colômbia, a fim de proporcionar aos contribuintes e administrações uma visão mais clara da figura.

Palavras-chave: Planejamento tributário agressivo; Objetivo principal; Tributação internacional; BEPS; Instrumento Multilateral. 


\section{Introducción}

La tributación, además de tener efectos en la economía interna, reviste una gran importancia en la inversión extranjera y en el comercio internacional, toda vez que es uno de los factores determinantes en la toma decisiones de las empresas interesadas en la realización de sus operaciones en un Estado determinado.

En efecto, en palabras de Jaques Spindler (2017):

Los impuestos están en el centro de muchos debates sobre su equidad, sus múltiples repercusiones en los precios, sus métodos de deducción... con todas sus consecuencias en términos de distribución de ingresos, de empleos, de acumulación de capital, crecimiento y desarrollo y también de elecciones individuales de consumo y ahorro (...) (p. 245).

Es por esto por lo que los Estados han visto la necesidad de recurrir a diferentes mecanismos, nacionales e internacionales, dentro de los que se encuentran los Convenios para evitar la Doble Imposición (en adelante, CDI), utilizados por los Estados para limitar su potestad tributaria y evitar que un mismo ingreso sea gravado en más de una jurisdicción, con la finalidad de promover y facilitar las relaciones comerciales entre sus nacionales y entre estos y los nacionales de otros Estados.

Actualmente, el sistema tributario internacional está conformado por una red de más de 3.000 Convenios para evitar la Doble Imposición, entre los cuales existe una gran cantidad de lagunas y fricciones que han generado situaciones de menor tributación o de doble no tributación. Lo anterior, sumado al uso abusivo de los CDI por parte de los contribuyentes y, en especial, de las empresas multinacionales, ha dado origen a un problema que cada vez llama más la atención de la comunidad internacional, en la medida en que los ingresos de los Estados se ven disminuidos pues "las empresas multinacionales han podido aprovechar la falta de coordinación en el sistema de tratados fiscales internacionales, a menudo, a través del uso de intermediarios en países con un sistema tributario más favorable, para minimizar su carga fiscal mundial” (Bammens \& De Broe, 2010, p. 51).

A causa de lo anterior, la Organización para la Cooperación y el Desarrollo Económico (en adelante, OCDE) en 2013 inició el desarrollo del Plan de Acción BEPS con la finalidad de mitigar los efectos de la erosión de las bases imponibles y el traslado de beneficios, el cual está conformado por 15 acciones en las cuales se proponen medidas tendientes a, entre otras cosas, evitar el uso abusivo de los convenios de doble imposición.

En ese sentido, dentro de las medidas propuestas por la OCDE en la Acción 6 de BEPS, cuyo objetivo es evitar el uso abusivo de los Convenios para evitar la Doble Imposición, se encuentra la de incluir en el convenio una cláusula general anti-abuso consistente en la aplicación del Test de Propósito Principal (en adelante, PPT), en virtud de la cual se nieguen los beneficios de un convenio cuando se pueda concluir razonablemente que el 
propósito principal o uno de los propósitos principales de una operación es la obtención de ese beneficio.

Ahora bien, en relación con la implementación de las medidas propuestas en el Plan de Acción, en la Acción 15 se propone la suscripción de un instrumento multilateral que modifique toda la red de CDI vigentes sin necesidad de que los Estados adelanten la renegociación individual de cada uno de ellos.

Así las cosas y teniendo en cuenta que la implementación y aplicación de las medidas propuestas en el Plan de Acción, en especial de la cláusula PPT, a través del Instrumento Multilateral (en adelante, MLI) puede tener efectos directos en los contribuyentes, en la medida en que es una forma de determinar qué operaciones pueden ser consideradas abusivas, resulta pertinente y necesario analizar el alcance y aplicación de dicha cláusula, en los términos planteados en el convenio multilateral diseñado por la oCDE en desarrollo de la Acción 15 y las vicisitudes que pueden presentarse en su incorporación a los CDI suscritos por Colombia para que, de esa manera, tanto los contribuyentes como las Administraciones tengan una visión más clara de la figura y puedan aplicarla de una manera más rigurosa. Es por lo anterior que este trabajo tiene como objetivo analizar la incorporación y aplicación de la cláusula general anti-abuso, contemplada en el artículo 7 del instrumento multilateral propuesto en desarrollo de la Acción 15 del Plan de Acción BEPs, en la red de Convenios para evitar la Doble Imposición suscritos por Colombia.

En consecuencia, este trabajo está dividido en tres acápites: en el primero, se explican los antecedentes del Plan de Acción BEPS y se describen las medidas sugeridas en la Acción 6 para evitar el uso abusivo de los Convenios para evitar la Doble Imposición y en la Acción 15, donde se propone la suscripción del instrumento multilateral; en el segundo, se exponen el alcance y los efectos generales de la cláusula de propósito principal consagrada en el artículo 7(1) del Instrumento Multilateral y, por último, en el tercero se analiza la aplicación de la cláusula PPT, en la red de CDI suscritos por Colombia, para lo cual se dividirán en tres grandes grupos, a saber: i) convenios que incluyen la PPT cumpliendo con los estándares del Plan de Acción; ii) convenios que, no obstante incluir una cláusula de propósito principal, esta no cumple con los estándares del Plan de Acción, y iii) convenios que no incluyen una cláusula de este tipo para, finalmente, proponer algunas conclusiones.

\section{EI Sistema tributario internacional}

\section{A. Antecedentes}

\section{EVOLUCIÓN Y DEFICIENCIAS}

La potestad tributaria, entendida como la facultad de los Estados de establecer tributos dentro de su territorio, ha sido tradicionalmente reconocida como una manifestación de la soberanía estatal. Si bien la potestad tributaria se encuentra circunscrita al territorio sobre el cual el Estado ejerce su soberanía, se pueden presentar casos en los que un hecho 
o situación ocurrido en un Estado resulte gravado por la legislación de otro, siempre que exista una conexión entre el contribuyente y ese otro Estado, debido a la aplicación de los criterios de sujeción real, de acuerdo con el cual la renta se grava en el lugar donde se produce, $\mathrm{y}$ personal, en virtud del cual las personas, consideradas residentes de un Estado, tributan sobre la totalidad de su renta sin importar que esta se haya generado en el exterior.

Teniendo en cuenta que, dentro del Derecho Internacional, no existen límites significativos a la soberanía fiscal, la potestad tributaria fue ejercida libremente por los Estados hasta las primeras décadas del siglo pasado.

En efecto, en los albores del siglo xx y, con mayor intensidad, después de la terminación de la Primera Guerra Mundial, se produjo un aumento de las relaciones comerciales entre las naciones que ocasionó, entre otras cosas, que la renta se generara en el ámbito de varios Estados. Lo anterior, sumado a la aplicación simultánea y poco coordinada de los criterios de sujeción, mencionados anteriormente, dio lugar al fenómeno de la doble imposición, el cual se presenta cuando "una misma renta o un mismo elemento del patrimonio se grava, en el mismo periodo, por dos o más Estados a través de un impuesto de la misma o similar naturaleza" (Falcón y Tella \& Pulido Guerra, 2010a, pp. 87-90) ${ }^{1}$.

Ante esta circunstancia, los Estados han recurrido, en primera instancia, a la implementación de medidas unilaterales tendientes a reducir o eliminar el impuesto exigido a un contribuyente sobre una renta gravada previamente en otro Estado, consistentes en la aplicación de los métodos de la exención, imputación y deducción los cuales, sin embargo, no eliminan la doble imposición internacional en todos los casos.

Así, teniendo en cuenta los efectos negativos de la doble imposición en relación con el desarrollo económico, la entonces Sociedad de las Naciones, para hacer frente a este problema, promovió la celebración de convenios bilaterales mediante los cuales los Estados limitaran su potestad tributaria, amén de facilitar el comercio internacional y promover el desarrollo económico, sentando, de esa manera, las bases del sistema tributario internacional que rige en la actualidad.

Posteriormente, finalizada la Segunda Guerra Mundial, con el objetivo de estimular las relaciones económicas internacionales, se intensificó la suscripción de Convenios para evitar la Doble Imposición promovidos, especialmente, por la Organización Europea de Cooperación Económica, que después se convertiría en la Organización para la Cooperación y el Desarrollo Económicos (OCDE).

Dicha organización, teniendo en cuenta el crecimiento acelerado del número de convenios suscritos entre los Estados y con la finalidad de homogeneizar las relaciones tributarias internacionales, propuso en 1963 un modelo de convenio, el cual ha sido utilizado

1 La doble imposición puede ser jurídica, cuando existe identidad de sujeto, además de la identidad del objeto gravado, de la identidad temporal y de la identidad del concepto tributario aplicado, o económica, cuando una misma renta se grava por dos tributos similares de dos Estados distintos, en el mismo periodo, pero en cabeza de sujetos distintos (Falcón y Tella \& Pulido Guerra, 2010). 
por la mayor parte de los Estados como base para la negociación y suscripción de sus Convenios para evitar la Doble Imposición.

En efecto, en los artículos 23A y 23B del Modelo de Convenio de la ocDE, el cual fue revisado y actualizado en los años 1977, 2003 y por última vez en 2008, se contemplan algunas medidas para eliminar la doble imposición internacional con base en el tipo de renta de que se trate y del Estado que se haya reservado la potestad de gravar esa renta, conforme a las reglas de distribución de la potestad tributaria establecidas en otras disposiciones del modelo (Falcón y Tella \& Pulido Guerra, 2010a, p. 100).

No obstante, la eficacia de los acuerdos cooperativos entre los Estados se ha visto limitada al objetivo de eliminar las barreras y a facilitar el libre comercio debido, en gran medida, al hecho de que el sistema tributario internacional, desde sus orígenes, se ha basado en la bilateralidad y en la competencia entre los Estados por atraer la inversión extranjera y al temor de algunos países, en especial de aquellos en vía de desarrollo, de perder parte de su recaudo fiscal con la suscripción de Convenios para evitar la Doble Imposición debido al desequilibrio entre la tributación en la residencia y en la fuente, presente en los convenios basados en el Modelo de la ocDE (Brauner, 2014, p. 65; Mosquera Valderrama, 2015, p. 618) $)^{2}$.

En efecto, de acuerdo con Brauner (2014):

(...) el régimen tributario internacional es y siempre ha sido sobre competencia. Los países se ven a sí mismos como competidores por la inversión y la renta. Las acciones colaborativas entre países se limitan a alcanzar la competencia perfecta, lograda mediante la eliminación de las fallas del mercado y la facilitación del libre comercio. Estos son los motivos que impulsaron la construcción del régimen tributario internacional y su evolución a lo largo de los años (pp. 64-65).

Hay que mencionar también que, desde finales del siglo pasado, se ha puesto en duda la eficiencia del sistema tributario internacional vigente, el cual, como se mencionó antes, está basado en la bilateralidad y en la competencia entre los Estados debido, principalmente, al cambio en las relaciones económicas, al desarrollo de la globalización y a la planeación fiscal agresiva de algunas empresas y grupos multinacionales.

En efecto, en los últimos años, las economías emergentes, como China, India y Brasil, han participado más activamente en el desarrollo del sistema tributario internacional lo cual, de acuerdo con algunos expertos, ha generado un retroceso en la tendencia a preferir la tributación en la residencia lo que, a su vez, genera una reducción en el nivel de estandarización del sistema tributario internacional (Brauner, 2014, p. 63).

2 Esta preocupación de los países en vía de desarrollo se pone de presente en el reporte realizado, en 2014, al G-20 por el Grupo de Trabajo sobre el impacto de BEPs en los países de bajos ingresos, en el que se indica que: "A further issue for developing countries, which was raised during the regional consultations, is the balance between source and residence taxation embodied in bilateral tax treaties modelled on the OECD and UN Model Tax Conventions" (Organización para la Cooperación y el Desarrollo Económicos [OCDE], 2014). 
Ahora bien, el desarrollo tecnológico que ha tenido lugar en las últimas décadas ha cambiado, entre otras cosas, la forma en que se realizan las transacciones económicas en la medida en que, gran parte de ellas, se realizan a través de medios tecnológicos con la participación de sujetos ubicados en diferentes jurisdicciones, lo cual ha dado origen a la denominada economía digital; lo anterior, sumado al auge del desarrollo de la globalización, ha producido un aumento inusitado en las transacciones comerciales transnacionales y en la movilidad de capitales, suscitando nuevos retos para la tributación internacional relacionados con temas como, por ejemplo, el comercio electrónico, los cuales no se encuentran regulados en la mayoría de los Convenios para evitar la Doble Imposición y que han comenzado a ocupar la atención de organismos internacionales como la ocDE ${ }^{3}$.

En ese sentido, la doctrina ha identificado algunos de los problemas que se originan debido al desarrollo de la economía digital como, por ejemplo, la determinación del país que tiene la potestad de gravar las operaciones de comercio electrónico, la falta de caracterización de las mismas y la aplicación de reglas de precios de transferencia a este tipo de transacciones realizadas entre empresas vinculadas y la cooperación fiscal internacional para el recaudo de impuestos entre países, entre otros (Sanín Gómez, 2015, p. 237).

A lo anterior se suma el hecho de que la inconsistencia del sistema tributario internacional, causada por la falta de coordinación entre los diferentes Estados en la regulación tributaria, ha permitido que los contribuyentes maximicen los beneficios de la planeación fiscal haciendo, en ciertos casos, un uso abusivo de los beneficios concedidos por convenios vigentes y propiciando, de esta manera, la creación de situaciones de menor tributación o de doble no tributación, en perjuicio de la hacienda pública de los Estados, conducta que se ha catalogado como planeación fiscal agresiva (Marín Benítez, 2017, pp. 88-89).

Esto, sumado al descontento social generado por el comportamiento de las empresas multinacionales y a los niveles históricos de erosión de las bases imponibles alcanzados en los últimos años, como lo constató la OCDE (2015) en el reporte final sobre la Acción 11, según el cual los Estados pierden entre el $4 \%$ y el $10 \%$ de la recaudación mundial por impuestos a las rentas empresariales; lo anterior puso de presente la necesidad de realizar una modificación sustancial e integral al sistema tributario internacional, que estuviera basada en la cooperación y coordinación entre los Estados y que permitiese dar una solución integral a los nuevos retos y problemáticas que se presentan en el campo de la tributación internacional.

En este contexto, surge en el año 2013 la iniciativa de diseñar el Plan de Acción contra la Erosión de las Bases Imponibles y el Traslado de Beneficios (BEPS, por sus siglas en inglés) la cual fue propuesta por el Reino Unido, con apoyo de Alemania y Francia, como respuesta al debate que estaba teniendo lugar en ese país con ocasión de la planificación

3 En efecto, una de las acciones contempladas en el Plan de Acción BEPs es la Acción 1, cuyo objetivo es identificar las principales dificultades que plantea la economía digital para la aplicación de las normas fiscales en vigor. 
fiscal internacional de algunas multinacionales; propuesta que, después de ser desarrollada a iniciativa propia por la ocDE, fue acogida por los demás países del G-20 ${ }^{[4]}$.

En desarrollo de dicha propuesta, la OCDE publicó el informe Adressing BEPS, en el que reconoció que la erosión de las bases imponibles es un riesgo para los ingresos tributarios, la soberanía fiscal y la equidad tributaria de los Estados, miembros y no miembros de la organización (OCDE, 2013). Además, en dicho informe, la OCDE resalta que la normativa tributaria internacional vigente no ha evolucionado a la par con las prácticas empresariales a nivel mundial pues, entre otras cosas, según Ramos Ángeles (2015, p. 383), los sistemas tributarios domésticos fueron diseñados en una época en la que el entorno económico con características distintas a las actuales, propias de un mundo globalizado y que es necesario abordar la problemática desde un enfoque integral, basado en el análisis de todos los factores de presión, en el que la coordinación entre los países será esencial para la búsqueda de soluciones efectivas.

En efecto, el Plan de Acción BEPS surge "como respuesta a la necesidad que, según la OCDE, existe en el marco de la globalización, de contar con unas prácticas coordinadas, que eviten el traslado de beneficios fiscales a otras jurisdicciones a través de prácticas abusivas, artificiosas o fraudulentas, así como la erosión de la base gravable al separar las materias imponibles" (Girón Uribe, 2018, p. 88).

En 2015, la ocDE publicó los resultados del desarrollo del Plan de Acción BEPs conformado por 15 acciones, encaminadas a hacer frente a los problemas que se vienen presentando en el régimen tributario internacional, desde principios del siglo xx, las cuales giran en torno a tres principios fundamentales, a saber: dotar de coherencia a las normas de Derecho interno que afecten actividades transfronterizas, reforzar el criterio de actividad sustancial contemplado por las normas internacionales vigentes, y mejorar la transparencia y la seguridad jurídicas para, de esa manera, restablecer la confianza en el sistema tributario internacional y procurar que los beneficios tributen en el lugar donde efectivamente se desarrollen las actividades económicas (oCDE, 2015).

En ese sentido, tal y como lo afirma Brauner (2014, p. 58), las acciones del Plan de Acción BEPS conllevan el reconocimiento por parte de la comunidad internacional de i) la necesidad de establecer un régimen tributario internacional basado en la cooperación entre los Estados y no en la competencia; ii) la importancia de una reforma sustancial al régimen tributario internacional que adopte soluciones sistemáticas y no coyunturales, y iii) la necesidad de aceptar que es indispensable adoptar soluciones innovadoras a algunos de los problemas del régimen, que no pueden ser resueltos con la aplicación de las instituciones tradicionales del sistema.

4 En efecto, autores como Hernandez González-Barreda (2017,p. 61) indican que el origen del Plan de Acción se encuentra en la reacción contra la planficación fiscal internacional que tuvo lugar en el Reino Unido en el año 2012, la cual se convirtió en una prioridad política para el Parlamento Británico, que se vendría a concretar en la propuesta del proyecto BEPS. 
Dentro de las acciones diseñadas en el Plan de Acción se encuentran, para lo que interesa a este trabajo, la Acción 6, que contiene medidas encaminadas a evitar el uso abusivo de los Convenios para evitar la Doble Imposición por parte de los contribuyentes y la Acción 15, la cual sugiere la suscripción de un convenio multilateral, para implementar algunas de las medidas sugeridas en las demás acciones, que permita la modificación expedita de los convenios bilaterales suscritos entre los Estados, sin que estos tengan que renegociarlos por separado.

\section{LA PLANEACIÓN FISCAL AGRESIVA Y EL USO ABUSIVO DE LOS CDI}

Para comprender el alcance de las medidas propuestas en BEPS, y en particular las encaminadas a evitar el uso abusivo de los Convenios para evitar la Doble Imposición, resulta necesario, en primer lugar, analizar la noción de planeación fiscal agresiva para, posteriormente, estudiar el concepto de abuso de los CDI en la medida en que el uso abusivo de los convenios se enmarca dentro de la planeación fiscal pues, en aras de reducir la carga fiscal, los contribuyentes, en algunos casos, buscan la concesión de beneficios previstos en los convenios en situaciones irregulares o inapropiadas.

En relación con la planeación fiscal, es pertinente mencionar que esta puede ser entendida como el conjunto de operaciones encaminadas a reducir el importe de la deuda fiscal, mediante la selección de una de las diferentes alternativas ofrecidas por el ordenamiento o, en palabras de Gloria Marín (2013, p. 333), como “aquellos comportamientos dirigidos a crear situaciones de ventaja patrimonial para los interesados deducida de sus propios actos o contratos, que se traduce en ahorro impositivo por comparación con el importe que habría sido exigido de no llevar a cabo esos actos o contratos".

El uso de las estrategias de planificación fiscal es consecuencia de dos defectos de los ordenamientos jurídicos: la falta de neutralidad y la falta de consistencia. Por una parte, la neutralidad es considerada como la cualidad de un sistema tributario que no influye en las decisiones de los individuos respecto de figuras económicas que produzcan un mismo resultado, lo cual permite que

(...) las decisiones de los sujetos puedan adoptarse sin tomar en cuenta el tratamiento fiscal de las diferentes alternativas, sino solo variables estrictamente económicas (retorno de la inversión, liquidez, riesgo-país, riesgo de la contraparte, etc.) o personales (Marín, 2013, p.51).

En ese orden de ideas, cuando un sistema tributario carece de neutralidad da lugar al surgimiento, por un lado, de opciones fiscales, que se configuran cuando el ordenamiento prevé dos consecuencias tributarias para un mismo supuesto de hecho cuya elección queda a discreción del contribuyente y, por otro lado, de vías menos gravadas, las cuales se presentan cuando el ordenamiento jurídico atribuye consecuencias fiscales distintas a dos operaciones que, siendo diferentes, producen el mismo resultado para el contribuyente. 
Estas figuras posibilitan la planificación fiscal en la medida en que, al dar un tratamiento tributario diferenciado a dos actos u operaciones que conllevan el mismo resultado económico, se dirige la conducta del contribuyente hacia aquel negocio que le resulta más favorable, pues "las situaciones a ambos lados de esta frontera son sustitutos perfectos entre ellos, con lo que los contribuyentes pueden cambiar su conducta para aprovecharse de la línea establecida" (Marín, 2013, p. 52).

Por otra parte, la falta de consistencia, entendida como una regulación insatisfactoria de determinadas figuras del sistema tributario, da lugar a los denominados arbitrajes fiscales, los cuales se concretan, de acuerdo con Shaviro (2004), en la posibilidad de obtener un tratamiento fiscal asimétrico para las distintas facetas de una operación que resulta en la obtención de una ventaja fiscal" (Marín, 2013, p. 60)

Así, siguiendo lo expuesto por Abelardo Delgado Pacheco (2015):

La planificación fiscal internacional no sería sino el aprovechamiento que hacen los grupos multinacionales o transnacionales de las diferencias entre los distintos ordenamientos fiscales nacionales o entre los diferentes ordenamientos vigentes en cada país o territorio con mayor o menor soberanía fiscal. En suma, esta planificación no es sino el resultado del arbitraje que permiten esas diferencias entre los ordenamientos de los distintos países o territorios (p.98).

Aunque esta figura se ha asimilado a la elusión fiscal, se diferencia fundamentalmente en que estas estrategias se desarrollan en un contexto internacional, mientras que la elusión fiscal en sentido estricto hace referencia al aprovechamiento de las inconsistencias de la normatividad interna de un Estado; así lo ha señalado la doctrina al indicar, no obstante las dos figuras comparten elementos tales como el aprovechamiento de las lagunas existentes en el ordenamiento jurídico, "en la planificación fiscal se aprovechan las lagunas o fricciones existentes en dos o más ordenamientos jurídicos” (Sánchez-Archidona, 2017,p. 144).

Ahora bien, de acuerdo con alguna parte de la doctrina, la planificación fiscal es una manifestación de la autonomía de la voluntad de los contribuyentes, la cual puede estar orientada a la búsqueda de un ahorro impositivo o de un tratamiento fiscal más favorable pues, tal y como lo ponen de presente autores como Calderón Carrero y Quintas Seara (2016), la planificación fiscal se enmarca "dentro de las posibilidades de autorregulación de intereses en que consiste la autonomía privada y la libertad de empresa".

Lo anterior no implica que la autonomía privada puede ser ejercida ilimitadamente pues, incluso cuando se ejerce con fines fiscales, se encuentra limitada por el ordenamiento jurídico, el orden público y la moral. Sin embargo, los motivos fiscales, a juicio de autores como Gloria Marín (2013), no traspasan por sí mismos ningún límite de legalidad u orden público debido a la imposibilidad de realizar un juicio ético respecto del monto del impuesto, pues este aspecto es competencia de la política, de donde se deduce que "el deber moral, como el deber cívico, de contribuir a los gastos comunes no llegan al punto de obligar al contribuyente a tomar el camino más provechoso para el tesoro". 
En efecto, diferentes jurisdicciones han reconocido la libertad de la que gozan los contribuyentes, en virtud de la cual pueden organizar su actividad con el objetivo de reducir la obligación tributaria.

A manera de ejemplo, el Tribunal de Justicia Europeo que, en sentencia de 12 de septiembre de 2006, indicó que la legitimidad de tener en cuenta consideraciones de contenido fiscal al momento de decidir el lugar de establecimiento de una filial, al indicar que

Por lo que se refiere a la libertad de establecimiento, el Tribunal de Justicia ha declarado ya que la circunstancia de que la sociedad se haya constituido en un Estado miembro con la finalidad de beneficiarse de una legislación más favorable no es, por sí sola, suficiente para llegar a la conclusión de que existe un uso abusivo de dicha libertad (Tribunal de Justicia Europeo, 2006, parr. 37).

En ese sentido, en Reino Unido, Her Majesty's Revenue and Customs (HMRC, 2015) ha reconocido que

Es totalmente legítimo que una empresa recurra a la planificación fiscal, por ejemplo, utilizando los beneficios para el propósito para el que fueron destinados (por ejemplo, reclamando una excención sobre la inversión de capital) o haciendo contribuciones a un plan de pensiones. Como parte del Código, se espera que las empresas eviten estructurar las transacciones de forma tal que tengan resultados impositivos que sean inconsistentes con las consecuencias económicas subyacentes a menos que exista una legislación específica que contemple ese resultado (p. 19).

Ahora, es necesario tener en cuenta que la ilicitud de un acto como lo es la planeación fiscal no reside en su propia naturaleza sino en el rechazo de este por parte del ordenamiento jurídico, por lo que el concepto de planificación fiscal ilícita o agresiva varía dependiendo de la postura que tome cada sistema tributario frente a este fenómeno, pues

El alcance de la lícita planificación fiscal no viene definido a priori y en abstracto en función de lo que por naturaleza está o no permitido, sino que viene establecido en cada ordenamiento tributario por exclusión, al establecerse los elementos, circunstancias o requisitos que permiten denegar las consecuencias fiscales de determinados actos o negocios jurídicos que van encaminados a la consecución de ahorro tributario (Marín, 2013, p. 43).

La calificación de la planeación fiscal como "agresiva" fue utilizada, por primera vez, en los Estados Unidos para catalogar negocios u operaciones contrarias a la finalidad de la norma. Por su parte, la OCDE, basándose en la concepción norteamericana, comenzó a delimitar este concepto en 2008, con el Estudio sobre el papel de los intermediarios fiscales (OCDE, 2008, pp. 10-11), identificando la planeación fiscal agresiva con aquella 
que implique adoptar una posición fiscal que posee fundamentos, pero que tiene consecuencias imprevistas y no deseadas sobre la recaudación tributaria y como aquella que implique la adopción de una posición fiscal favorable para el contribuyente sin revelar la existencia de un cierto grado de incertidumbre sobre si ciertos aspectos de la declaración tributaria resultan ajustados a la ley, sin que se haya alcanzado una definición concreta de este concepto ${ }^{5}$.

Ahora bien, el concepto de planeación fiscal agresiva, entendida como la utilización por parte de los contribuyentes de estrategias encaminadas a reducir el monto de la obligación tributaria, contrarias al espíritu o a la finalidad de las normas tributarias (dentro de las que se encuentran las disposiciones de los Convenios para evitar la Doble Imposición), ha sido ampliamente criticada debido a su vaguedad y subjetividad, pues no existen factores objetivos que permitan determinar cuál es la finalidad de una norma, creándose, de esa manera, zonas grises en las que la calificación de la licitud o ilicitud de una operación queda a discreción de las administraciones tributarias.

Sin embargo, teniendo en cuenta que, como ya se mencionó, el concepto de planificación fiscal agresiva puede variar dependiendo de cada ordenamiento jurídico en particular y que uno de los propósitos de la OCDE con el Plan de Acción BEPS es la armonización del sistema tributario internacional, se comparte el criterio de Calderón Carrero y Quintas Seara (2016, p. 21), en el sentido de afirmar que la noción planeación fiscal agresiva utilizada por esta organización no pretende crear un nuevo concepto que prevenga la utilización de estrategias fiscales abusivas, sino que tiene como finalidad reducir la extensión del concepto de planeación fiscal legítima, excluyendo de esta categoría operaciones que, en principio, podrían considerarse ajustadas a Derecho y justificar el cambio de paradigma del sistema tributario internacional.

En efecto, tal y como lo afirman los autores mencionados, al referirse a la utilización del concepto de planeación fiscal agresiva en el Plan de Acción BEPs:

A nuestro juicio en este último ámbito se hace un uso más instrumental de tal concepto para limitar por vía interpretativa el concepto de planeación fiscal legítima mediante la categorización como planificación fiscal agresiva (pseudo-ilegal) de operaciones que se ajustan a la letra pero no al espíritu de la ley; (...). Asimismo, podría decirse que el Plan de Acción BEPs emplea el concepto de planificación fiscal agresiva para explicar las disfuncionalidades, lagunas e inconsistencias del actual sistema de fiscalidad internacional al objeto de justificar la construcción de un marco más consistente y coherente que actualice dicho sistema de fiscalidad internacional (Calderón Carrero y Quintas Seara, 2016,pp.21-22).

5 Por su parte, la HMRC (2015, p. 38) ha definido la planeación fiscal agresiva como "la aplicación de las normas del sistema tributario para obtener beneficios fiscales no queridos por el Parlamento. Que implica actuar conforme al texto, pero no al espíritu, de la ley". 
De lo anterior se infiere que la planeación fiscal, entendida en los términos antes mencionados, no es per se ilícita o agresiva, toda vez que "es legítimo para los contribuyentes planificar sus actividades con el objeto de minimizar su carga fiscal u obtener beneficios del Estado, siempre y cuando los procedimientos utilizados sean legales" (Beltrán Losada, J., 2011, p. 19).

Sin embargo, se torna agresiva o ilícita, en el ámbito internacional, cuando el contribuyente, mediante la utilización de figuras o mecanismos artificiosos, se aprovecha de las lagunas o diferencias existentes entre distintas jurisdicciones tributarias con la finalidad de obtener ventajas fiscales a las que, en principio, no tendría derecho.

Una forma de planeación fiscal agresiva, favorecida por la globalización, la competencia fiscal y por la ya mencionada inconsistencia del sistema tributario internacional, es el traslado de beneficios, que se configura, siguiendo a Ramos Ángeles (2015, p. 380), cuando las empresas colocan sus utilidades en un país de baja o nula imposición, a pesar de que estas se generaron en un territorio distinto con un nivel de tributación menos favorable, mediante medios, instrumentos, estructuras o contratos artificiosos que no responden a la real sustancia económica de las actividades que desarrollan, dando lugar al fenómeno de la erosión de las bases imponibles.

Un ejemplo de este fenómeno se puede encontrar en el caso de las compañías multinacionales que, como Google, por ejemplo, obtuvo en 2011 ingresos de aproximadamente USD 38 billones y utilidades de USD 10 billones; sin embargo, su tasa efectiva de tributación en ese año fue del 2,4\% cuando la tasa legal de tributación en los Estados Unidos es del $35 \%$ (Van den Hurk, 2014, pp. 29-30).

Los efectos negativos de la erosión de las bases imponibles no solo afectan a los Estados, que se ven obligados a reajustar sus presupuestos en la medida en que se ven privados de los recursos necesarios para ejecutar sus políticas públicas y prestar los servicios a su cargo, sino que también perjudican a los contribuyentes, quienes terminan soportando la falta de contribución de las empresas multinacionales (Sanchez-Archidona, 2017, pp. 152-153).

Ahora, si bien la erosión de las bases imponibles causada por la planeación fiscal agresiva por parte de las empresas multinacionales no es un tema nuevo en el ámbito de la tributación internacional, sus efectos negativos se hicieron más notorios con la crisis económica del año 2008, en la medida en que los gobiernos afectados por la crisis, como por ejemplo el de los Estados Unidos, no contaban con los recursos suficientes para implementar las medidas destinadas a mitigar los efectos de la crisis y reactivar la economía, tal y como lo afirman algunos autores:

(...) la carencia de fondos públicos pudo haberse cubierto (al menos una gran porción) con los impuestos a los que tenían derecho estos países y que habían sido eludidos por las MNEs, entre otros, mediante el traslado de beneficios (Ramos Ángeles, 2015, pp. 381-382). 
Una vez analizada la noción de planeación fiscal agresiva, es necesario considerar que algunas de las estrategias utilizadas por los contribuyentes, constitutivas de este fenómeno, pueden consistir en la utilización abusiva de los CDI, siendo este aspecto de la planeación fiscal el eje principal de la Acción 6; es por esto por lo que resulta pertinente continuar con la delimitación de la noción de uso abusivo de los CDI utilizada por la oCDE en el diseño de esta acción.

Sobre este punto, es necesario partir del supuesto de que, tal y como se indica en el comentario al artículo 1 del Modelo de Convenio de la oCDE, el objetivo principal de los convenios es promover los intercambios de bienes y servicios y los movimientos de capitales y personas mediante la eliminación de la doble imposición internacional, así como evitar la elusión y la evasión fiscales.

Así las cosas, el uso abusivo del convenio se presenta cuando un contribuyente, aprovechándose de las lagunas y/o de las diferencias existentes en los ordenamientos tributarios de uno o de ambos Estados contratantes, adquiere beneficios previstos en el convenio en supuestos en los que la obtención de estos beneficios no estaba prevista, contraviniendo, de esa manera, la finalidad del convenio. Este uso abusivo de los Convenios para evitar la Doble Imposición se ve favorecido por la existencia de una gran cantidad de CDI que posibilitan la utilización de figuras jurídicas artificiales en busca de obtener beneficios fiscales en determinadas legislaciones.

En ese orden de ideas, siguiendo a Rozo Gutiérrez (2016, p. 128), el abuso de los convenios podría analizarse "desde una perspectiva subjetiva, es decir, el uso de un CDI por parte de personas a quienes los convenios no estaban destinados a beneficiar y, desde el punto de vista objetivo, o sea, el uso de mecanismos que buscan una regla distinta de distribución de la competencia prevista en el CDI".

Así, constituyen ejemplos de supuestos de uso abusivo de los Convenios para evitar la Doble Imposición, desde una perspectiva subjetiva, el caso en que una persona actúa a través de una entidad jurídica constituida en un Estado fundamentalmente para conseguir los beneficios de convenios que no podría obtener directamente $y$, desde una perspectiva objetiva, cuando una persona física, con vivienda permanente y participación en una sociedad radicada en un Estado contratante, con el objeto de vender dichas acciones y evitar el gravamen previsto en dicho Estado para las ganancias obtenidas de esa operación, traslada su vivienda permanente al otro Estado contratante, en el que esas ganancias se someten a un gravamen reducido o nulo ${ }^{6}$.

Ahora bien, en el Informe Final de la Acción 6, la oCDE identifica dos escenarios en los que se busca la concesión de beneficios en circunstancias inapropiadas, a saber, aquellos casos en los que se busca eludir las limitaciones previstas en el propio convenio y aquellas

6 Si bien en este caso la persona física cumpliría con el requisito de residencia del otro Estado contratante, la operación resultaría abusiva toda vez que, de acuerdo con el ejemplo, fue realizada con la única finalidad de obtener un tratamiento fiscal más favorable. 
situaciones en las que el contribuyente trata de eludir la aplicación de una norma tributaria doméstica utilizando los beneficios del convenio (OCDE, 2015, p. 17).

En el primer escenario, relativo a los casos en los que el contribuyente busca eludir las limitaciones previstas en el propio convenio, el Informe Final (OCDE, 2015, pp. 73-74) se refiere, entre otras situaciones, al fraccionamiento de contratos en que las sociedades dividen un negocio jurídico en varias partes, con duraciones para cada una inferiores a los doce meses previstos en el artículo 5(3) del Modelo de Convenio, asignándolas a sociedades diferentes pero que pertenecen al mismo grupo, con la finalidad de evitar la configuración de un Establecimiento Permanente y, en consecuencia, evitar que los beneficios obtenidos en desarrollo de esa operación sean gravados de acuerdo con las disposiciones del CDI. Otro ejemplo podrían ser las operaciones que pretenden eludir la calificación de dividendo para así beneficiarse de una calificación del convenio, como por ejemplo, la de ganancia de capital.

También, dentro de las conductas incluidas en esta primera categoría se mencionan, con especial énfasis, las estrategias de treaty shopping, las cuales, partiendo de la base de que para ser destinatario de los beneficios de un Convenio para Evitar la Doble Imposición el sujeto debe estar incluido dentro del ámbito personal de aplicación del mismo, lo cual sucede cuando el contribuyente es residente de uno de los Estados contratantes en los términos del artículo 4 del Modelo de Convenio de la OCDE, buscan ampliar el ambito de aplicación subjetiva del tratado .

Así las cosas, las estrategias de treaty shopping serían todas aquellas mediante las cuales un tercero no residente en un Estado, con la utilización de, por ejemplo, sociedades pantalla ubicadas en Estados distintos al de su residencia, obtiene un beneficio contemplado en un CDI, que dicho Estado prevé, exclusivamente, para sus residentes. En ese sentido, de acuerdo con el International Tax Glosary (International Bureau of Fiscal Documentation [IBFD], 2006), este concepto:

Es normalmente aplicado a situaciones en las cuales al menos una de las partes no es un residente de buena fe de un país del cual se busca protección conforme al convenio; por ende, el contribuyente está habilitado para reclamar beneficios fiscales a los cuales no podría de otra manera tener derecho (Morales Arias, 2010, p. 121).

Una de las estrategias de treaty shopping consiste en el uso de sociedades instrumentales, descritas por la oCDE en el Double Taxation Conventions and the Use of Conduit Companies (1986). Estas sociedades obtienen directamente los beneficios contemplados en las disposiciones del CDI de un Estado, en virtud de su calidad de residentes, pero el beneficio económico derivado de dicho privilegio está en cabeza de una persona a la que dicho convenio no le resulta aplicable; un ejemplo de esta modalidad de treaty shopping es el siguiente: una persona $X$, residente de un Estado que no ha suscrito ningún CDI, obtiene intereses de créditos a su favor a cargo de compañias localizadas en otros Estados, bajo cuyas leyes dichos intereses están sujetos a retención en la fuente (1); X, constituye la 
sociedad Y en el Estado A, que tiene una extensa red de CDI y transfiere los créditos a dicha compañía; los intereses pagados a esa compañía están sometidos a una baja o nula tributación en el Estado A, debido a las excenciones previstas para compañias de ese tipo (2). Con fundamento en la red CDI suscritos por el Estado A, la sociedad Y alega la reducción de la retención en la fuente cobrada en los Estados donde se generan dichos intereses (3). Los interes recibidos por la sociedad $\mathrm{Y}$ son transferidos a $\mathrm{X}$ como pago de un préstamo (4) (OCDE, 1986, p. 3)

Figura 1. Ejemplo de estrategia de Treaty Shopping

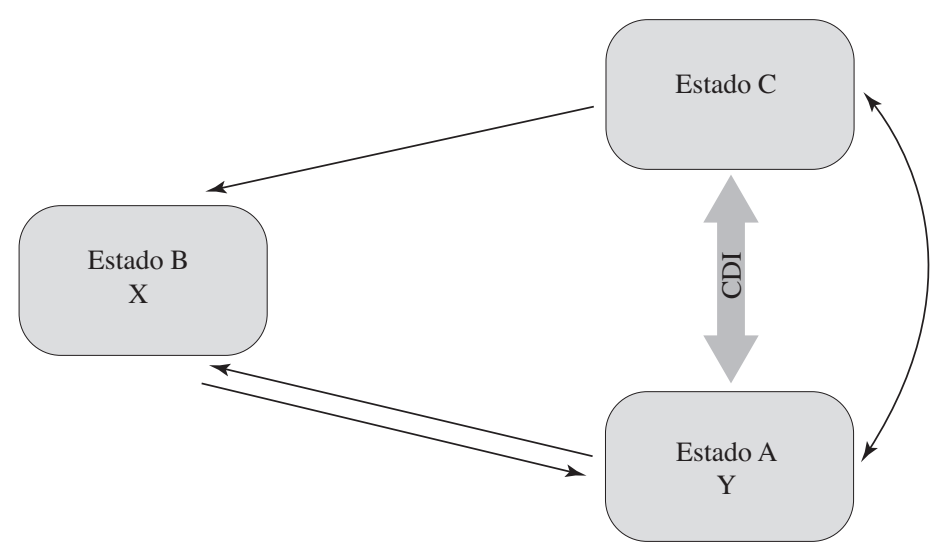

Fuente: Elaboración propia.

Otra modalidad de treaty shopping son las denominadas stepping stone strategies que, siguiendo a Morales Arias (2010, p. 123), se puede ejemplificar en el supuesto en que una sociedad , residente en el Estado Z, es acreedora de una obligación en cabeza de otra sociedad residente del Estado Y, entre los cuales no existe un CDI, por lo que los intereses pagados por la sociedad en $\mathrm{Y}$ a la sociedad en $\mathrm{Z}$ están sujetos a la retención regular conforme al Derecho interno de Y; en estas circunstancias, y con la finalidad de reducir el porcentaje de la retencion aplicada sobre dichos intereses, la sociedad en $\mathrm{Z}$ cede el crédito a favor de una sociedad residente en el Estado W, el cual sí cuenta con un CDI con Y, a cambio de la suscripción de un título a cargo de esa sociedad en favor de la sociedad en Z.

De esa manera, la sociedad en Y le paga los intereses a la sociedad en W, sobre los cuales se aplica una retención menor o nula, de conformidad con el CDI los cuales, en consecuencia, tienen una carga fiscal neutra, pues se deducen los intereses pagaderos a la sociedad residente en $\mathrm{Z}$, no sujetos a retención en el momento del pago.

7 Hay que mencionar que dicho pago se realiza en un escenario en el que está presente un CDI o una regulación doméstica más beneficiosa de manera que la tributación sobre dichos intereses sea menor o nula. 
En relación con el segundo escenario, esto es, los casos en los que se pretende eludir una norma interna amparándose en los beneficios de un CDI, la OCDE reconoce que la erosión de las bases imponibles no solo proviene del uso directo de los convenios, sino que, en algunas ocasiones, estos facilitan las prácticas elusivas.

En este caso, si bien el informe final no lo menciona de manera expresa, se está haciendo referencia a lo que, en la doctrina, se conoce como Rule Shopping, entendiendo por tal aquellas operaciones realizadas por individuos que, estando dentro del ámbito de aplicación subjetiva de un CDI, buscan que se aplique una norma más favorable de la que, en principio, les sería aplicable. En este tipo de transacciones el contribuyente "normalmente elude una regla distributiva de competencia de un convenio para obtener la aplicación de otra regla de distribución que proporciona beneficios adicionales" (Báez, 2016, p. 29). Así, dentro de este supuesto se pueden incluir estrategias de subcapitalización, doble residencia ${ }^{8}$, operaciones de arbitraje fiscal ${ }^{9}$, entre otras.

En ese orden de ideas, el Rule Shopping se presenta en las llamadas operaciones de strip de dividendos, la cual se puede ilustrar con el siguiente ejemplo: $\mathrm{X}$ es una sociedad residente en el Estado A y es propietaria de acciones de la sociedad Y, residente en el Estado B el cual cuenta con un CDI suscrito con el Estado A. De acuerdo con lo dispuesto en el convenio $\mathrm{X}$, puede transmitir las acciones de $\mathrm{Y}$ sin tributar por la ganancia obtenida en el Estado B, por lo que $\mathrm{X}$ decide vender todas sus acciones a la sociedad Z, también residente en el Estado B, antes de que Y distribuya los dividendos; inmediatamente después de realizada la distribución de los dividendos, $\mathrm{X}$ readquiere todas sus acciones por un precio fijado teniendo en cuenta el monto de los dividendos distribuidos.

Así las cosas, en los supuestos de Rule Shopping, la concesión de los beneficios contemplados en un CDI se tornaría inadecuada cuando cause la elusión del impuesto interno por lo que, si bien algunas de las operaciones mencionadas son objeto de otras acciones del Plan de Acción, lo que se busca con la Acción 6 es procurar que la concesión de beneficios no impida la aplicación de las normas internas respectivas pues, siguiendo lo expuesto en el Informe Final de la Acción 6, "la concesión de los beneficios previstos en las disposiciones del convenio en estos casos se consideraría inadecuada en la medida en que provoque la elusión del impuesto interno" (OCDE, 2016b).

\section{B. La Acción 6: medidas para evitar el uso abusivo de los CDI}

Para la OCDE, una de las principales causas de la erosión de las bases imponibles es el uso abusivo de los convenios de doble imposición, en especial a través del treaty shopping, que permite a los individuos de terceros Estados no contratantes acceder a beneficios

8 Ejemplo de este tipo de prácticas puede ser una sociedad que es residente de un Estado de acuerdo con la legislación interna pero que no ostenta tal calidad de acuerdo con el CDI.

9 En estos casos el contribuyente se aprovecha de los vacíos o de las inconsistencias de la legislación interna de un Estado en materias como, por ejemplo, la calificación de las rentas o el tratamiento de los contribuyentes. 
previstos en los convenios en situaciones en las que la concesión de dichos beneficios no estaba prevista, afectando, de esa manera, el recaudo de los Estados.

En esa medida, la Acción 6 del Plan de Acción BEPs tiene por objetivo desarrollar disposiciones convencionales y recomendaciones relativas al diseño de normas internas que impidan la concesión de los beneficios del convenio en circunstancias inapropiadas. Esta acción, de acuerdo con el Informe Final de la Acción 6, publicado por la ocDE en 2015, se desarrolla en tres áreas encaminadas a: i) desarrollar disposiciones modelo para el convenio y recomendaciones para el diseño de normas internas para impedir la concesión de beneficios en circunstancias inapropiadas, ii) aclarar que los convenios no fueron concebidos para provocar situaciones de doble no imposición y iii) identificar las consideraciones de política fiscal que deben tener en cuenta los países al momento de suscribir un Convenio para evitar la Doble Imposiciones con otro país (OCDE, 2015).

\section{Medidas ANTI-ABUSO}

Con miras a cumplir con el primero de los objetivos enunciados en precedencia, en la Acción 6 se propone una serie de medidas para impedir la utilización abusiva de los CDI por parte de los contribuyentes. No obstante, es importante señalar que algunos supuestos de uso abusivo de los CDI ya han sido objeto de tratamiento convencional y doméstico por parte de los Estados como, por ejemplo, mediante la introducción en los ordenamientos jurídicos internos de figuras originadas en el Derecho internacional, como el beneficiario efectivo o a través la implementación de normas relacionadas con los precios de transferencia ${ }^{10}$.

Sin embargo, tal y como lo pone de presente la oCDE (2015, pp. 18-19), en el Informe Final de la Acción 6, actualmente existen supuestos de treaty shopping que no alcanzan a estar cubiertos por las disposiciones del Modelo de Convenio de la OCDE y es poco probable que las normas anti-abuso internas sean adecuadas para prevenir el uso abusivo de los convenios en los casos en los que lo que se pretende eludir sea una disposición del mismo convenio, por lo que se recomienda a los Estados introducir en sus CDI normas que impidan la concesión de beneficios en los casos en los que se haga un uso abusivo del CDI.

Así, para hacer frente al uso abusivo de los convenios de doble imposición por parte de los contribuyentes se recomienda, en primer lugar, incorporar al convenio una disposición que, de manera clara, indique que los convenios, además de propender por evitar la doble imposición, buscan evitar la generación de situaciones de doble no tributación o de tributación reducida a través de la elusión, la evasión o las prácticas de treaty shopping.

También se propone la inclusión de una cláusula de limitación de beneficios (LOB, por sus siglas en inglés), que limite la concesión de los privilegios previstos en los Convenios para evitar la Doble Imposición al cumplimiento de ciertos requisitos objetivos, y/o de una

10 En el ordenamiento jurídico colombiano, por ejemplo, la figura del beneficiario efectivo se encuentra consagrada en los artículos 631-5 y 631-6 del Estatuto Tributario. 
norma general anti-abuso, en la forma del test de propósito principal (PPT, por sus siglas en inglés), que sea aplicable a los supuestos de uso abusivo de los convenios no cubiertos por la LOB; normas que, en todo caso, deberán ser complementadas por las normas domésticas anti-abuso de cada Estado en la medida en que, tal y como lo reconoce la ocDE, la cláusula de limitación de beneficios y el test de propósito principal no resultan suficientes en los supuestos en los que se pretenda eludir disposiciones internas.

Sin embargo, la OCDE reconoce que, en la implementación de las medidas propuestas, en el Plan de Acción se deben tener en cuenta las condiciones particulares de cada Estado pues, en efecto, siguiendo lo indicado en el Informe Final de la Acción 6, algunos Estados pueden verse limitados por sus Constituciones en la adopción de las recomendaciones propuestas en el Plan de Acción, puede que un Estado ya cuente con normas internas anti-abuso que hagan innecesaria la inclusión de las normas propuestas en el Plan de Acción o puede suceder que la capacidad administrativa de la Administración tributaria de un Estado le impida aplicar ciertas normas detalladas del convenio (OCDE, 2015, p. 14).

Es por lo anterior que la adopción de las recomendaciones propuestas en esta acción debe hacerse con cierto grado de flexibilidad, razón por la cual, en el informe final, se ofrecen diferentes alternativas para la implementación de dichas recomendaciones con la salvedad de que, sea cual sea la forma en que un Estado decida implementarlas, se debe garantizar un estándar mínimo consistente en la inclusión de medidas que sean idóneas y capaces de evitar los supuestos de abuso de convenio descritos en el Informe Final, el cual indica que como mínimo los Estados deberían insertar en sus convenios tributarios "una declaración expresa en la que se indique que la intención común de los Estados contratantes es eliminar la doble imposición sin generar situaciones de doble no imposición o de tributación reducida, a través de la elusión o evasión fiscales o de las estrategias de treaty shopping" (OCDE, 2015, pp. 19-20).

\section{La Acción 15: el instrumento multilateral}

El régimen tributario internacional está compuesto por una extensa red de más de 3.000 tratados bilaterales suscritos entre los Estados, algunos de los cuales se remontan a los años 20 del siglo pasado, estando la mayoría de dichos convenios basada en modelos, como el de la ONU o el Modelo de Convenio de la OCDE, los cuales se han venido actualizando y modificando a lo largo del tiempo. Sin embargo, es un hecho que la inclusión de las modificaciones o actualizaciones realizadas a dichos modelos en el texto de los CDI suscritos por cada Estado requiere de una gran cantidad de recursos y tiempo, lo cual ha tenido como consecuencia el aumento de las discrepancias entre los CDI vigentes facilitando, de esta manera, la erosión de las bases imponibles, sumándose a lo anterior que "la arquitectura de los convenios bilaterales no fue pensada para abordar niveles elevados de movilidad de factores y cadenas globales de valor" (ocDE, 2015).

Así las cosas, teniendo en cuenta que algunas de las medidas previstas en el Plan de Acción BEPS conllevan la modificación de los convenios de doble imposición y que, como 
se mencionó en precedencia, la renegociación individual de los mismos representa para los Estados la inversión de una gran cantidad de tiempo y de recursos, la ocDE, en la Acción 15 del Plan BEPS, propone la creación de un instrumento multilateral que modifique simultáneamente todos los CDI, que sean incluidos por los Estados, amén de garantizar la rápida aplicación de las medidas propuestas en el Plan de Acción atendiendo los cambios acelerados que se presentan en la economía global y la necesidad de adaptarse a ellos.

En ese orden de ideas, el Instrumento Multilateral (MLI, por sus siglas en inglés) tiene como finalidad la introducción en el texto de los CDI vigentes de las medidas propuestas en el Plan de Acción que estén directamente relacionadas con los convenios, es decir, que impliquen su modificación, como algunas de las contenidas en las acciones 2, 6, 7 y 14 o, en caso de que los Estados opten por no incorporar en sus CDI las medidas propuestas por el Plan de Acción, garantizar en virtud de la suscripción del Instrumento Multilateral, que se cumpla con el estándar mínimo fijado por la OCDE que, en relación con la Acción 6 , consiste en la inclusión de medidas que sean idóneas y capaces de evitar los supuestos de abuso de convenio descritos en el Informe Final, en particular los de treaty shopping ${ }^{11}$.

En este punto, es importante resaltar que, como lo pone de presente Hernández González-Barreda (2017, p. 57), la novedad en la aplicación de las medidas del Plan de Acción está en el Instrumento Multilateral, pues la propuesta de suscribir un instrumento multilateral que produzca "los mismos efectos que una renegociación simultánea de miles de convenios fiscales bilaterales" (OCDE, 2015), representa un cambio trascendental y sin precedentes en el régimen tributario internacional ya que, por una parte, pone de presente la voluntad política de los Estados de cooperar en la lucha contra la erosión de las bases imponibles, dando un giro al sistema tributario internacional tradicionalmente basado en la competencia y, por otra parte, permite implementar las medidas del Plan Acción de una manera rápida y sincronizada sin modificar la naturaleza bilateral de los convenios y sin menoscabo de la soberanía fiscal de los Estados $^{12}$.

Adicionalmente, la propuesta de la Acción 15 permitiría brindar una mayor seguridad jurídica a los contribuyentes pues al contar con un texto unificado, habría más posibilidades de lograr una interpretación uniforme de los CDI en las diferentes jurisdicciones en la medida en que

(...) el instrumento internacional aborda de forma definitiva una serie de cuestiones controvertidas que afectan a las normas tributarias internacionales, puede servir tanto para aclarar la situación en la que se encuentran varias normas de las que dependen las

11 Lo anterior en la medida en que, teniendo en cuenta que el MLI es un tratado internacional, su suscripción origina la obligación en cabeza de los Estados de cumplir con el Estándar mínimo.

12 Para la OCDE (2015) las ventajas derivadas de la implementación de la Acción 15 dependen del respeto por la bilateralidad y la soberanía fiscal, pues de lo contrario se correría el riesgo de que en el proceso se estanque o que en él participen pocos países. 
empresas a la hora de realizar inversiones a nivel transnacional, como así también para garantizar certidumbre en el futuro (OCDE, 2105).

Empero, la pretensión de coherencia del instrumento multilateral se ve truncada, en cierta medida, si se tiene en cuenta que, como se verá más adelante, en el MLI se concede a los Estados un amplio margen de flexibilidad en la implementación de las disposiciónes del Instrumento Multilateral lo que, lejos de lograr la homogeneización de los convenios, lo que provocaría sería el aumento de las diferencias entre estos.

A lo anterior se suma que el MLI solo surte sus efectos respecto de los CDI que, estando vigentes al momento de la suscripción del instrumento, sean incluidos por los Estados firmantes y que, además, las modificaciones realizadas en virtud del MLI pueden ser diferentes para cada uno de los CDI cubiertos, en la medida en que las reservas autorizadas por el instrumento multilateral no tienen que adaptarse del mismo modo respecto de todos los convenios incluidos por un Estado.

Así, por ejemplo, los Estados firmantes tienen derecho a no aplicar la totalidad de una disposición del Instrumento Multilateral, de modo que esta no surta efectos entre el Estado que formule la reserva y los demás Estados Parte del MLi y no se modifiquen las disposiciones de los CDI cubiertos suscritos entre ellas como, por ejemplo, las normas relativas a las entidades transparentes, a las entidades con doble residencia, al abuso mediante establecimientos permanentes situados en terceros Estados, etc.

Todo lo anterior ha contribuido a que algunos expertos hayan puesto en duda la eficacia del MLI para implementar las medidas del Plan de Acción de manera rápida, armónica y coherente:

Porque el elevado número de alternativas, exclusiones y reservas, sobre todo si se realizan CDI por CDI, puede dar lugar a que subsistan diferencias que afecten a la consistencia del nuevo marco de la tributación internacional, creando nuevas distorsiones que podrían ser empleadas para nuevas planificaciones fiscales (Zornoza, 2017, p. 495).

Por otra parte, es necesario tener en cuenta que el MLi no modifica ni deroga directamente el texto de los Convenios cubiertos, sino que coexiste con estos de manera que lo que se modifica es la aplicación de estos, razón por la cual el instrumento contempla varias cláusulas de compatibilidad encaminadas a dar una solución anticipada a las controversias que puedan presentarse entre las disposiciones de los CDI y las del MLI.

Lo anterior, contrario al propósito con el cual fue propuesto el MLI relacionado con garantizar una mayor certeza a los contribuyentes

(...) no puede dejar de señalarse que ello incrementará la ya notable complejidad normativa existente en el ámbito de la tributación internacional, con riesgo para la seguridad jurídica de los contribuyentes trasnacionales, a los que no resultará sencillo 
-sin un asesoramiento experto- determinar las reglas que les son aplicables (Zornoza, 2017, p. 498).

No obstante, si bien, como se indicó anteriormente, el MLI pone de presente la voluntad política y el compromiso de los Estados en la implementación del Plan de Acción y en la lucha contra el fenómeno de la erosión de las bases imponibles y el traslado de beneficios, lo anterior no implica que con el MLI la adopción de medidas unilaterales se convierta en la regla general en el ámbito de la tributación internacional el cual continuará teniendo un carácter eminentemente bilateral.

Sin embargo, a pesar de todo lo anterior, la adopción del instrumento multilateral representa una gran oportunidad para garantizar y consolidar la eficacia de las medidas del Plan de Acción. En efecto, el compromiso de la comunidad internacional frente a la adopción del instrumento multilateral queda demostrado con su entrada en vigor el 1 de julio de 2018, tres meses después del depósito del quinto instrumento de ratificación por parte de la República de Eslovenia ${ }^{13}$.

\section{El Instrumento Multilateral (MLi)}

El 24 de noviembre de 2016, el grupo ad hoc designado por la OCDE para la elaboración del texto del instrumento multilateral, que contó con la participación de un gran número de Estados, jurisdicciones no estatales y organizaciones internacionales, finalizó la redacción del texto del instrumento, quedando abierto para la firma a partir del 31 de diciembre de ese año ${ }^{14}$.

Ahora, el instrumento multilateral como "una medida de carácter instrumental respecto a los restantes contenidos del paquete BEPs relacionados con los tratados" (Zornoza, 2017) limita su contenido a la inclusión en los CDI de: i) disposiciones dirigidas a neutralizar el tratamiento de los mecanismos híbridos, ii) disposiciones para la prevención del abuso de los convenios, iii) disposiciones relativas a la prevención de la elusión artificiosa de la condición de establecimiento permanente y iv) disposiciones dirigidas a mejorar el funcionamiento de los mecanismos de resolución de litigios.

Asimismo, conviene destacar, como lo afirma Zornoza (2017), que el MLI está integrado por un "núcleo duro" integrado por estándares mínimos relacionados con la prevención del uso abusivo de los convenios, tratados en la Acción 6, consistente, como ya se mencionó, en la inclusión de una declaración expresa en la que se indique que los convenios

13 A partir de esa fecha, de acuerdo con el artículo 34.1 del MLI, el instrumento entrará en vigor para los demás Estados contratantes el primer día del mes siguiente a la expiración del periodo de tres meses contados desde la fecha del depósito del instrumento de ratificación.

14 Esto muestra, de acuerdo con Zornoza (2017), el carácter inclusivo del Plan de Acción, pues la aplicación Plan de Acción beps se quiere extender más allá de los países miembros de la ocde para incluir a los países no miembros y países en vía de desarrollo. 
no tienen como propósito la generación de situaciones de doble no imposición o de tributación reducida y a la mejora de resolución de controversias, a la que hace referencia la Acción 14, encaminado a aumentar la eficacia del procedimiento amistoso de solución de controversias.

\section{Implementación de las medidas de la Acción 6 del Plan de Acción beps}

Sobre este punto, es necesario tener en cuenta por una parte que, como se mencionó en precedencia, la Acción 6 del Plan de Acción propone, para evitar el uso abusivo de los CDI, tres opciones, a saber: i) incorporar al convenio una disposición que, de manera clara, indique que los convenios, además de propender por evitar la doble imposición, buscan evitar la generación de situaciones de doble no tributación o de tributación reducida a través de la elusión, la evasión o las prácticas de treaty shopping; ii) la inclusión de una cláusula general anti-abuso, consistente en la adopción del test de propósito principal (PPT); iii) la adopción de una cláusula limitativa de beneficios (LOB), detallada o simplificada, que limite la concesión de los privilegios previstos en los Convenios para evitar la Doble Imposición al cumplimiento de ciertos requisitos objetivos, o iv) una combinación de las dos anteriores.

Así, el artículo 6 (1) del MLI dispone la modificación de los convenios comprendidos de manera que, en el preámbulo, se incluya lo siguiente:

Con la intención de eliminar la doble imposición en relación con los impuestos comprendidos en este convenio sin generar oportunidades para la no imposición o para una imposición reducida mediante evasión o elusión fiscales (incluida la práctica de la búsqueda del convenio más favorable que persigue la obtención de los beneficios previstos en este convenio para el beneficio indirecto de residentes de terceras jurisdicciones).

Por su parte, la cláusula general, es decir el PPT, de acuerdo con el artículo 7(2) del MLI, reemplazaría las disposiciones de los convenios cubiertos que nieguen la totalidad o una parte de los beneficios contemplados en el tratado cuando el propósito principal o uno de los propósitos principales sea la obtención de esos beneficios; lo anterior, atendiendo a que las cláusulas generales anti-abuso de los diferentes convenios pueden variar respecto de la no concesión de todos los beneficios o de los beneficios concedidos bajo determinados artículos del convenio, como por ejemplo, dividendos, intereses o regalías.

Por su parte, la LOB simplificada puede ser aplicada de manera complementaria junto con la cláusula PPT siempre que los Estados parte del convenio cubierto consientan en ello; empero, de acuerdo con el artículo 7(7) del MLI, la LOB simplificada podrá ser aplicada, siempre que los Estados contratantes, que no hayan optado por su aplicación, lo acepten expresamente, de manera simétrica, caso en el cual la LoB será aplicada por ambas partes, o de manera asimétrica, situación en la que el Estado contratante que haya optado por la 
aplicación de la LOB podrá aplicarla junto con el PPT, mientras que su contraparte solo podrá aplicar esta última.

Al igual que la cláusula general, la LOB simplificada remplazará las cláusulas de limitación de beneficios existentes o será incluida en el tex to de los convenios cubiertos cuando estos no contengan este tipo de disposiciones.

Además, el artículo 7(4) del MLi contempla que los Estados tienen la posibilidad de incluir una disposición en los convenios que les permita a las autoridades tributarias, a petición de los contribuyentes, realizar una consulta bilateral para conceder los beneficios de un CDI, en los casos en los que el contribuyente no supere el PPT, la cual solo será aplicable cuando todas las partes contratantes de un CDI cubierto opten por su inclusión en el texto del convenio y así lo notifiquen al depositario.

De la misma manera, es necesario tener en cuenta que el MLI es un instrumento flexible pues, atendiendo a que, tal y como lo pone de presente la OCDE (2015, p. 24), no todos los Estados están dispuestos a asumir los mismos compromisos en la adopción del Plan de Acción, esto ofrece diferentes opciones para la implementación de las medidas del paquete BEPS, de donde se deduce que no hay una única manera para suscribir el instrumento.

\section{AltERnATIVAS DE IMPLEMENTACIÓN}

En efecto, en relación con las medidas propuestas en la Acción 6, de la lectura de los parágrafos 15, 16 y 17 del artículo 7 del MLI, se puede concluir que en la implementación de las medidas tendientes a evitar el uso abusivo de los convenios los Estados es posible optar por una de las siguientes cuatro opciones:

Los Estados pueden, de conformidad con el artículo 7(15)(a) del MLI, decidir no aplicar la regla del propósito principal, de la manera prevista en el artículo 7(1), cuando pretendan buscar, mediante una negociación directa con su contraparte, la implementación de una cláusula detallada de limitación de beneficios o una manera diferente de cumplir con el estándar mínimo contemplado por la Acción 6, caso en el cual surge para los Estados la obligación de negociar la inclusión de la cláusula detallada de limitación de beneficios, del test de propósito principal o de una medida que les permita cumplir con el estándar mínimo.

También, los Estados pueden optar por la no aplicación de la regla del propósito principal y de la consulta bilateral, de acuerdo con el artículo 7(15)(b) o de la LOB simplificada, según el artículo 7(15)(c), cuando en los convenios cubiertos, ya contengan este tipo de disposiciones de la manera prevista en el MLI.

En relación con la regla del propósito principal, el artículo 7(17)(a) del MLI dispone que cuando un Estado no haya realizado la reserva del literal a del artículo 7(15), es decir que no haya optado por la negociación bilateral, deberá notificar al depositario cuáles de sus convenios cubiertos, frente a los cuales no haya realizado la reserva del literal b del mismo artículo, contienen una disposición que niegue la totalidad o una parte de los beneficios cuando el propósito principal o uno de los propósitos principales de una operación es la 
obtención de esos beneficios, indicando el artículo y el parágrafo en el que se encuentre dicha cláusula.

Así, cuando los Estados contratantes de un CDi concuerden en la cláusula que consideran que cumple con lo mencionado anteriormente, la regla del propósito principal consagrada en el artículo 7(1) de MLI entrará a reemplazar dicha disposición; en caso contrario, el MLI aplicará solo en los casos en los que las disposiciones del CDI le sean contrarias.

También, el MLI dispone que cuando un Estado realice la notificación en los términos arriba mencionados, podrá manifestar que acepta la aplicación de la regla del propósito principal de manera provisional, mientras se lleva a cabo la negociación bilateral tendiente a introducir una cláusula de limitación de beneficios que complemente o reemplace la de propósito principal contenida en el artículo 7(1) del MLI.

Otra de las opciones consiste en que, de acuerdo con el artículo 7(16), cuando un Estado decida aplicar únicamente la LOB simplificada, puede optar por inaplicar la totalidad del artículo 7 del MLi a sus convenios cubiertos cuando una o más de las otras jurisdicciones contratantes no haya optado por la aplicación de dicha cláusula ni haya permitido su aplicación, en los términos del artículo 7(7) arriba mencionados. En estos casos, los Estados contratantes deberán adelantar una negociación bilateral tendiente a implementar las medidas que garanticen el cumplimiento de los estándares mínimos previstos por la Acción 6.

\section{Suscripción DEL MLI POR PARTE DE COLOMBIA RESPECTO DE LA PPT}

Una vez analizadas las formas en las que se pueden implementar las medidas del Plan de Acción BEPS relacionadas con el uso abusivo de los CDI, puede identificarse cuál fue la postura adoptada por el Estado colombiano.

$\mathrm{Al}$ respecto, es pertinente mencionar que Colombia suscribió el MLI el 7 de junio de 2017, incluyendo como tratados cubiertos por el MLi los suscritos con Canadá, Chile, República Checa, España, Francia, India, la República de Corea, México, Portugal y Suiza.

Además, en relación con el artículo 7 del MLI, Colombia optó por la opción prevista en el artículo 7(17)(a), es decir que al no realizar la reserva prevista en el literal a del artículo 7(15), aceptó la aplicación de la regla de propósito principal del artículo 7(1) de manera provisional mientras negocia la adopción de una cláusula de limitación de beneficios que complemente o remplace la regla de propósito principal y, además, optó por la aplicación de la LOB simplificada de manera complementaria.

Ahora, cumpliendo con la notificación establecida en el artículo 7(17)(a) del MLI, el Estado colombiano considera que algunos de sus convenios no están sometidos a la reserva prevista en el artículo 7(15)(b) y que ya cuentan con una disposición que niegue la totalidad o una parte de los beneficios cuando el propósito principal o uno de los propósitos principales de una operación es la obtención de esos beneficios, como son los relacionados en la Tabla 1. 
Tabla 1. Elaboración Propia, nOtificación REALIZAda POR El Estado COlOMbiano EN LOS TÉRMINOS DEL ARTÍCULO 7(17)(A) DEL MLI

\begin{tabular}{|l|l|}
\hline \multicolumn{1}{|c|}{ CDI } & Artículo contentivo de la regla PPT \\
\hline Canadá & $26(1)$ \\
\hline Chile & $27(3)$ \\
\hline República Checa & $25(1)$ y $25(3)$ \\
\hline Francia & $10(8), 11(8), 12(7), 20(4)$ y $26(1)$ \\
\hline India & $28(2)$ y $28(3)$ \\
\hline República de Corea & $26(1)(a)$ y $26(1)(b)$ \\
\hline Portugal & $26(3)$ \\
\hline
\end{tabular}

Fuente: Elaboración propia.

Así, a manera de ejemplo, el artículo 26(1) del Convenio, para evitar la doble imposición y para prevenir la evasión fiscal en relación con el impuesto sobre la renta y sobre el patrimonio suscrito con Canadá, dispone que

Las disposiciones de los artículos 10, 11 y 12 no se aplicarán si el propósito o uno de los principales propósitos de cualquier persona relacionada con la creación o atribución de una acción, crédito o derecho, en relación con los cuales los dividendos, intereses o regalías se pagan, fuera el obtener beneficios de uno o más de estos artículos mediante tal creación o atribución (Ley 1459, 2011).

Del mismo modo, en el Convenio para evitar la Doble Imposición suscrito entre Colombia y Portugal, el artículo 26(3) dispone que

Las disposiciones del presente Convenio no se aplicarán si el propósito principal o uno de los propósitos principales de cualquier persona relacionada con la creación o asignación de la propiedad o de un derecho con respecto de los cuales se pagan las rentas fue el de tomar ventaja de estas disposiciones por medio de dicha creación o asignación (Ley 1692, 2013).

Por último, el Convenio suscrito entre Francia y Colombia, el cual aún no ha sido ratificado, dispone, entre otros, en su artículo 26(1), lo siguiente:

No obstante las disposiciones de cualquier otro artículo de este Convenio, un residente de un Estado Contratante no podrá beneficiarse en el otro Estado Contratante de ninguna reducción o sometimiento a impuestos en virtud del Convenio, si el objetivo principal o uno de los objetivos principales de la realización de operaciones por parte de dicho residente o de una persona vinculada con ese residente es obtener los beneficios previstos en este Convenio. 
Ahora, para efectos de este trabajo resulta necesario conocer las posiciones adoptadas por los países que han suscrito CDI con Colombia y que fueron incluídos como convenios cubiertos al momento de la firma del MLI. En ese sentido, las posiciones adoptadas al momento de la suscripción del MLi se resumen en la siguiente tabla ${ }^{15}$ :

\section{Tabla 2. Posiciones adoptadas por los Estados contratantes DE LA RED DE CDI SUSCRITOS POR COLOMBIA}

\begin{tabular}{|l|l|c|}
\hline \multicolumn{1}{|c|}{ Otro Estado contratante } & \multicolumn{1}{|c|}{ Notificación art. 7(17)(a) del mli } & Coincidencia \\
\hline Canadá & $26(1)$ & Sí \\
\hline Chile & $27(3)$ & Sí \\
\hline República Checa & $25(1)$ y $25(3)$ & Sí \\
\hline España & - & - \\
\hline Francia & $10(8), 11(8), 12(7), 20(4)$ y 26(1) & Sí \\
\hline India & $28(2)$ y 28(3) & Sí \\
\hline República de Corea & $26(1)(a)$ y 26(1)(b) & Sí \\
\hline México & - & Sí \\
\hline Portugal & $26(3)$ & \\
\hline Suiza & $\begin{array}{l}\text { No se incluyó el CDI con Colombia como convenio cubierto por } \\
\text { el MLI. }\end{array}$ & \\
\hline
\end{tabular}

Fuente: Elaboración propia.

\section{Cláusula de Propósito Principal (PPT)}

Tal y como ya se puso de presente, el uso abusivo de los Convenios para evitar la Doble Imposición es un problema que ha venido ocupando la atención de la ocDE desde hace varios años ${ }^{16}$; sin embargo, solo hasta 2015, con el Plan de Acción BEPS, se plantearon medidas vinculantes de carácter internacional para hacer frente a esta situación que, hasta ese momento, había sido regulada por el Derecho interno de cada Estado, siguiendo lo contemplado en el párrafo 7 del comentario al artículo 1 del Modelo de Convenio de la oCDE el cual disponía que

(...) los contribuyentes pueden verse tentados a abusar de las normas tributarias aprovechándose de las diferencias entre las leyes de varios Estados. Estos intentos deben ser enfrentados por las normas o reglas jurisprudenciales que hagan parte del derecho doméstico del Estado afectado.

15 Es necesario anotar que las posiciones adoptadas cada uno de los Estados firmantes pueden cambiar hasta el momento del depósito del instrumento de ratificación.

16 En efecto, la ocDE comenzó a estudiar esta problemática desde 1977. 
En efecto, si bien desde 2003 la oCDE había contemplado, en los comentarios al artículo 1 Modelo de Convenio, la figura del Guiding Principle, en virtud de la cual los beneficios de un convenio no deberían ser concedidas cuando el objetivo principal para realizar ciertas transacciones fuese obtener un tratamiento fiscal más favorable y este tratamiento fuese contrario al espíritu de las normas del tratado, esta disposición, al no hacer parte del articulado del modelo de convenio, es solo un criterio de interpretación del mismo, de acuerdo con los artículos 31 y 32 de la Convención de Viena sobre Derechos de los Tratados (CVDT), por lo que los Estados se vieron obligados a adoptar internamente normas generales anti-abuso que, en consecuencia, tienen caracteres particulares en cada ordenamiento jurídico como, por ejemplo, el artículo 689 del Estatuto Tributario Colombiano que dispone que la Administración Tributaria puede recaracterizar o reconfigurar cualquier operación que constituya abuso en materia tributaria y, consecuentemente, desconocer sus efectos ${ }^{17}$.

Es por esto que autores como Andrés Báez (2016) consideran que la cláusula de propósito principal no introduce nada nuevo en lo relacionado con el diseño legal del presupuesto de aplicación de las normas generales anti-abuso, pues los ordenamientos internos de un gran número de países ya contaban con normas de este este tipo, por lo que la OCDE, en el diseño de la cláusula de propósito principal, en palabras del autor, "más que edificar sobre la nada dicho presupuesto, esto es, el estándar de lo que constituye o no abuso, tenía ante sí la difícil tarea de elegir la opción técnicamente más consistente” (Báez, 2016, p. 11).

Así las cosas, la cláusula del propósito principal resulta ser la primera regla general anti-abuso estandarizada en ser introducida en el articulado del Modelo de Convenio de la OCDE y en tener fuerza vinculante en la medida en que los Estados la adopten a través de la suscripción del Instrumento Multilateral; sin embargo, esta regla presenta algunos problemas técnicos en su aplicación que serán explicados más adelante.

Ahora bien, para estudiar el alcance de la regla del propósito principal contenida en el MLI es necesario partir del análisis del texto literal de la norma tal y como fue redactado en el artículo 7(1) del instrumento, el cual dispone:

No obstante las disposiciones de un Convenio fiscal comprendido, los beneficios concedidos en virtud del mismo no se otorgarán respecto de un elemento de renta o de patrimonio cuando sea razonable concluir, teniendo en cuenta todos los hechos y circunstancias pertinentes, que el acuerdo u operación que directa o indirectamente genera el derecho a percibir ese beneficio tiene entre sus objetivos principales la obtención del mismo, excepto cuando se determine que la concesión del beneficio en esas circunstancias es conforme con el objeto y propósito de las disposiciones pertinentes del Convenio fiscal comprendido

17 De acuerdo con esa norma, una operación o serie de operaciones constituye abuso cuando involucre el uso o la implementación de uno o varios actos o negocios jurídicos artificiosos, sin razón o propósito económico y/o comercial aparente, con el fin de obtener provecho tributario, independientemente de cualquier intención subjetiva adicional. 


\section{A. Ámbito de aplicación}

En relación con el ámbito de aplicación del PPT, es pertinente mencionar que, de acuerdo con el texto antes citado, este se encuentra limitado al convenio en el que se incluya dicha disposición, pues la regla solo será aplicable respecto de los beneficios concedidos en virtud de las disposiciones de un Convenio fiscal comprendido que, de acuerdo con el artículo 2 del Instrumento Multilateral, son aquellos Convenios para evitar la Doble Imposición en materia de impuesto sobre la renta que estén en vigor entre dos o más partes y respecto de los cuales cada uno de los Estados contratantes haya notificado su inclusión como un convenio que se busca que sea modificado por el MLI.

En ese orden de ideas, los beneficios tributarios concedidos en virtud de normas de Derecho doméstico o de otros tratados celebrados por uno o ambos de los Estados contratantes no podrán ser denegados invocando la PPT incluida en un CDI cubierto, aun cuando "tuviesen un ámbito de aplicación personal o sustantivo similar" (Lang, 2014, p. 656).

\section{B. Estructura}

Sobre este punto es necesario mencionar que, si bien algunos elementos de la regla del propósito principal pueden llegar a ser muy generales y/o ambiguos como, por ejemplo, las expresiones "razonable concluir" u "objeto y propósito de las disposiciones pertinentes"; lo anterior obedece a que la OCDE en el diseño de la PPT tenía como propósito que esta fuese aplicable al mayor número de casos posibles en los que se pudiera dar la concesión de beneficios en situaciones inapropiadas.

Teniendo en cuenta lo anterior, respecto de la estructura de la cláusula de propósito principal, del texto de la norma puede deducirse que la PPT se compone de tres elementos, a saber: i) la existencia de un beneficio derivado de una operación o transacción; ii) un elemento subjetivo, consistente en que la obtención de ese beneficio sea uno de los propósitos principales para la realización de esa operación o transacción, y iii) un elemento objetivo, que supone que la obtención de ese beneficio sea contraria al objeto y propósito de las disposiciones pertinentes del CDI.

\section{EXISTENCIA DE UN BENEFICIO}

En cuanto al primer elemento, esto es, la existencia de un beneficio y teniendo en cuenta el tenor literal de la PPT, de acuerdo con el cual "los beneficios concedidos en virtud de este no se otorgarán respecto de un elemento de renta o de patrimonio cuando sea razonable concluir, teniendo en cuenta todos los hechos y circunstancias pertinentes, que el acuerdo u operación que directa o indirectamente genera el derecho a percibir ese beneficio (...)", es necesario mencionar, por un lado, que las expresiones acuerdo u operación deben ser entendidas en un sentido amplio de manera que incluyan cualquier acuerdo, transacción 
o serie de transacciones, sean o no legalmente exigibles. En ese sentido, el comentario al artículo 29 del Modelo de Convenio de la oCDE dispone que estas expresiones

En particular, incluyen la creación, cesión, adquisición o transferencia de los ingresos en sí, o de la propiedad o derecho con respecto al cual se generan los ingresos. Estos términos también abarcan acuerdos relativos al establecimiento, adquisición o mantenimiento de una persona que percibe los ingresos, incluida la calificación de esa persona como residente de uno de los Estados Contratantes, e incluyen los pasos que las personas pueden tomar para establecer su residencia (OCDE, 2017, p. 590).

Además, de acuerdo con el comentario, los beneficios pueden ser obtenidos mediante la realización de una sola operación o mediante la ejecución de una serie de operaciones que, en conjunto, permitan la concesión del beneficio. Así, un ejemplo de acuerdo u operación sería el caso en el que las reuniones de la junta directiva de una sociedad sean llevadas a cabo en un país distinto para alegar el cambio de residencia de la persona jurídica.

Por otro lado, el término beneficios puede ser entendido, siguiendo lo establecido en el comentario antes mencionado, como "todas las limitaciones sobre los gravámenes impuestos en el Estado de origen, el alivio de la doble imposición, la protección otorgada a los residentes y nacionales de un Estado contratante o cualquier otra limitación similar (OCDE, 2017, p. 589)", dentro de las que podría mencionarse, a manera de ejemplo, la limitación del derecho del Estado de la fuente a gravar los dividendos, intereses o regalías generados en eses Estado y pagados a un residente en otro Estado ${ }^{18}$.

Por su parte, la doctrina ha considerado que para hablar de beneficio es necesario que, como consecuencia de la aplicación de las disposiciones del convenio, se verifique un tratamiento más favorable para el contribuyente en comparación con aquel que resultaría si se aplicasen las normas de Derecho interno o, también, de la aplicación de otras disposiciones del convenio aplicables al caso concreto (Lang, 2014, p. 657).

Con base en lo anterior podría afirmarse, a manera de ejemplo, que no es posible obtener beneficios de la aplicación de las normas relacionadas con las definiciones, como las contempladas en los artículos 1 a 3 del MCOCDE, pues, en palabras de autores como Vikram Chand (2018), estas no conceden ningún beneficio concreto y deben ser analizadas en concordancia con las demás normas del tratado.

\section{Elemento SubJetivo}

A propósito del elemento subjetivo de la PPT, la norma dispone que el beneficio obtenido por un contribuyente podrá ser denegado cuando se pueda concluir razonablemente que "el acuerdo u operación que directa o indirectamente genera el derecho a percibir ese beneficio tiene entre sus objetivos principales la obtención del mismo”, para lo cual la

De acuerdo con el artículo 10, 11 y 12 del MCOCDE. 
Administración Tributaria, para decidir si aplica o no la PPT, deberá realizar un análisis objetivo de todos los hechos y circunstancias presentes al momento de la celebración del acuerdo u operación respectivo.

Ahora, si bien no hay claridad respecto de cuáles son los hechos y circunstancias relevantes a efectos de determinar el o los propósitos principales de un acuerdo o transacción, de los ejemplos propuestos por la OCDE en los comentarios a la PPT puede deducirse que deben tenerse en cuenta, entre otros aspectos: i) la naturaleza del acuerdo o transacción, ii) las actividades realizadas por las partes, iii) el nivel de autonomía de las partes intervinientes en la operación y iv) la magnitud del beneficio fiscal obtenido en comparación con el beneficio no fiscal obtenido con la transacción ${ }^{19}$.

La aplicación de este elemento resulta clara en los casos en los que la Administración Tributaria, después de realizar el análisis objetivo mencionado en la PPT, llega a la conclusión de que el propósito principal o, en otras palabras, el único propósito que motivó la realización de la operación fue la obtención del beneficio tributario y, en ese caso, la regla produciría todos sus efectos, sin perjuicio de que el contribuyente pueda demostrar que la obtención del beneficio se ajusta al objeto y propósito de las disposiciones del Convenio.

Empero, los problemas se presentan cuando, además de los motivos fiscales, concurren motivos no fiscales en el desarrollo de las operaciones de un contribuyente; en principio, teniendo en cuenta que la regla de propósito principal dispone que la obtención del beneficio se encuentre entre los objetivos principales de la operación, podría afirmarse que el problema antes enunciado es aparente pues, de concurrir propósitos fiscales con otros propósitos, la Administración Tributaria podría aplicar la PPT y, en consecuencia, denegar la concesión del beneficio.

Sin embargo, lo anterior, además de conceder un poder exorbitante y arbitrario a la Autoridad Fiscal que terminaría afectando la seguridad jurídica de los contribuyentes, desconocería el hecho de que, teniendo en cuenta que las empresas buscan obtener ganancias derivadas de la realización de su actividad, las operaciones o transacciones que se realicen en desarrollo de la misma pueden verse motivadas por fines comerciales y/o económicos que pueden concurrir con el objetivo de obtener un tratamiento tributario más favorable, lo cual no implica que el fin tributario sea el motivo principal de la operación.

En efecto, esta interpretación de la PPT resulta contraria a la esencia y finalidad de los Convenios para evitar la Doble Imposición, pues no hay que olvidar que, esto lo ponen de presente algunos autores.

19 Así, por ejemplo, refiriéndose a este último criterio, el Tribunal de Justicia Europeo, en la decisión C-126/10 de 10 de noviembre de 2011 indicó que: "nada se opone, en principio, a que una operación de fusión que lleve a cabo una reestructuración o una racionalización de un grupo que permita reducir los gastos administrativos y de gestión de éste pueda tener motivos económicos válidos. No obstante, ese no es el caso de una operación de absorción, como la controvertida en el litigio principal, en el que parece resultar que, habida cuenta de la amplitud de la ventaja fiscal que se pretende obtener, a saber, más de 2 millones de euros, el ahorro realizado por el grupo de que se trata en términos de costes estructurales es completamente marginal" (TJE, 2011). 
(...) los CDI son instrumentos que pretenden eliminar los perniciosos efectos de la doble imposición jurídica internacional favoreciendo el intercambio de bienes y servicios, la circulación de las personas y la transferencia de tecnología y, por ese motivo, muchas de las inversiones transnacionales sencillamente no se harían en ausencia de tales convenios (Baéz, 2016, p. 17).

Es por lo anterior que tanto la OCDE como la doctrina han buscado la manera de mitigar los efectos del elemento subjetivo presente en la PPT, restringiendo su interpretación; de ahí que se pueda afirmar que no se cumple con el elemento subjetivo cuando sea razonable concluir que la obtención del beneficio no fue una consideración principal para la realización de la operación o de la serie de operaciones que resultaron en ese beneficio lo cual sucedería, por ejemplo, en los casos en los que una operación esté estrechamente relacionada con la actividad comercial principal de una empresa y su realización atienda a motivos económicos y no tributarios, aun cuando la obtención de un beneficio pueda ser una consecuencia indirecta de la realización de dicha operación.

A manera de ejemplo, el comentario al artículo 29 del Modelo de Convenio de la OCDE propone la siguiente situación: X, una empresa residente en el Estado A, se dedica a la producción de zapatos deportivos; debido a la rápida expansión del negocio, la empresa está considerando el establecimiento de una fábrica en un país en vía de desarrollo con el objetivo de beneficiarse de los bajos costos de manufactura. Después de realizar un estudio preliminar, la empresa determina como posibles opciones para el establecimiento de la fábrica en tres países con condiciones económicas y políticas similares por lo que, teniendo en cuenta que el Estado A tiene un CDI vigente cono el Estado C, decide construir la fábrica en dicho Estado.

En este ejemplo, teniendo en cuenta que el tratamiento tributario fue un factor determinante en la selección de la empresa X podría afirmarse, en principio, que uno de los propósitos principales que motivó su decisión fue la existencia de un CDI suscrito entre los Estados A y C por lo que, atendiendo al tenor literal de la PPT, los beneficios de dicho convenio podrían ser denegados.

No obstante, desde otro punto de vista, se puede alegar que, si bien la decisión fue tomada atendiendo el tratamiento tributario más favorable que obtendría la empresa debido a la existencia del CDI entre los Estados A y C, es claro que este no fue el propósito principal que motivó la realización de la operación pues esta obedeció a la intención de la empresa X de expandir el negocio y de beneficiarse de los bajos costos de la mano de obra del Estado C, razón por la cual, en este caso, no se cumpliría con el elemento subjetivo de la PPT y, en consecuencia, no podrían negarse los beneficios concedidos por el convenio alegando su aplicación.

Al respecto, el comentario al artículo 29 del Convenio de la OCDE indica que

En este ejemplo, no se puede concluir razonablemente que uno de los propósitos principales para construir la fábrica sea la obtención de los beneficios del tratado. 
Además, dado que un objetivo general de los convenios tributarios es fomentar la inversión transfronteriza, obtener los beneficios del cDI celebrado entre los Estados A y B para la inversión en la construcción de la fábrica está de acuerdo con el objeto y el propósito de las provisiones de ese Convenio (OCDE, 2017, p. 592).

Por su parte, autores como Vikram Chand (2018) proponen interpretar el elemento subjetivo de la PPT de manera que, en los casos en los que se concluya que la operación fue realizada de buena fe, es decir, que su ejecución atendió a motivos comerciales y económicos, siendo la obtención de un tratamiento tributario más favorable un efecto accesorio, la PPT no pueda ser aplicada. En efecto, el autor afirma que

En otras palabras, cuando los propósitos no tributarios sean los principales impulsores de la transacción, no se puede argumentar que uno de los propósitos principales sea obtener un beneficio fiscal. Por lo tanto, el elemento subjetivo debe interpretarse de manera restrictiva en el sentido de que la transacción o acuerdo en juego tiene una justificación económica o comercial que supera la ventaja fiscal obtenida, entonces este elemento no se cumple (Chand, 2018, p. 23).

No obstante, la introducción de este elemento en el texto de la regla de propósito principal conlleva el surgimiento de problemas relacionados con la igualdad, toda vez que operaciones que sean objetivamente iguales podrían resultar siendo gravadas de forma distinta y con la seguridad jurídica de los contribuyentes, en la medida en que no existen parámetros objetivos que permitan determinar cuando el propósito principal de una operación es la obtención de un beneficio tributario, quedando esta decisión sujeta al arbitrio de las administraciones tributarias.

\section{ELEMENTO OBJETIVO}

Respecto del tercer y último elemento, esto es el objetivo, la PPT dispone que no se negarán los beneficios obtenidos en virtud de las disposiciones de un Convenio cuando "se determine que la concesión del beneficio en esas circunstancias es conforme con el objeto y propósito de las disposiciones pertinentes del Convenio Fiscal Comprendido" lo cual implica, en otras palabras, que cuando se verifique el elemento subjetivo, el contribuyente podrá demostrar que la concesión del beneficios se ajusta al propósito de las disposiciones del tratado. Sobre este punto resulta pertinente realizar las siguientes observaciones.

En primer lugar, es necesario tener en cuenta que determinar el objeto y propósito de las "disposiciones relevantes" de un CDI resulta complicado, pues, entre otras cosas, los CDI son negociados y redactados de forma general sin hacer especial énfasis en el propósito de las partes al incluir determinada regla en articulado del tratado y que, a simple vista, las disposiciones de un Convenio no tienen un propósito en propio sino que su única finalidad es servir como herramientas para alcanzar el fin último de los CDI, esto es, 
fomentar el comercio internacional mediante la eliminación de la doble imposición. Es por esto por lo que las "disposiciones relevantes" del convenio deben ser interpretadas a la luz del objeto y propósito de todo el tratado pues, de lo contrario, la interpretación aislada de estas disposiciones, en los términos antes mencionados, conllevaría la inaplicación de la PPT en la medida en que siempre se cumpliría con el elemento objetivo, pues “(...) las prácticas abusivas de un contribuyente cumplen formalmente con las condiciones impuestas por las disposiciones pertinentes de un tratado para lograr su efecto (no tributación total o parcial de los ingresos en uno o ambos Estados contratantes)" (Kuzniacki, 2018, p. 265).

En ese sentido, para determinar el objeto y propósito de un CDI, teniendo en cuenta su naturaleza de tratado internacional, es necesario acudir a la Convención de Viena sobre Derecho de los Tratados (CVDT), que en su artículo 31(1) dispone que "un tratado deberá interpretarse de buena fe conforme al sentido corriente que haya de atribuirse a los términos de tratado en el contexto de estos y teniendo en cuenta su objeto y propósito".

Ahora, de acuerdo con el artículo 31(2) de la CVDT, el contexto comprende, entre otras cosas, el preámbulo del tratado. En ese orden de ideas, se debe considerar que, como se mencionó anteriormente, dentro de las medidas propuestas en la Acción 6 para evitar el uso abusivo de los Convenios para evitar la Doble Imposición se incluye la de modificar el preámbulo de los CDI indicando que los CDI no tienen como finalidad la creación de situaciones de no imposición o de baja tributación.

Así las cosas, a partir de la entrada en vigor del MLI deberá tenerse en cuenta la interpretación de las disposiciones relevantes de un CDI, para determinar si se cumple o no con el elemento objetivo que impediría de la aplicación de la PPT, que además de propender por estimular y facilitar el comercio entre los Estados contratantes, los convenios buscan evitar los supuestos de doble no imposición y/o de imposición reducida.

Lo anterior pone en evidencia la relación existente entre la regla PPT y el preámbulo de los CDI, en la medida en que "por un lado, la PPT le da contenido al nuevo preámbulo. Por el otro lado, el nuevo preámbulo influye en cómo deben interpretarse los diversos elementos de la PPT" (Kuzniacki, 2018, p.240).

En ese orden de ideas, al realizar una interpretación de las disposiciones de un tratado a la luz del nuevo preámbulo de los CDI, podría llegarse a afirmar que estas tienen varios propósitos. De ahí que se comparta lo afirmado por la doctrina en el sentido de indicar que

Esto se debe a que tienen como objetivo eliminar la doble imposición sin crear oportunidades para la evasión fiscal, incluido el Treaty Shopping, para mejorar el comercio internacional. La eliminación de la doble imposición y la prevención de la evasión fiscal constituyen su principal objetivo operacional, mientras que la mejora del entorno del comercio internacional es el objetivo último del tratado y, por lo tanto, de tales disposiciones. Esto significa que cualquier intento de definir el propósito de las disposiciones relevantes a través de los fines definitivos y operativos será circular. Los propósitos son todos identificados por sí mismos y entre sí (Kuzniacki, 2018, p. 266). 
En segundo lugar, hay que considerar lo establecido en los CMOCDE, donde se indica que la persona a la que se le niegue un beneficio tiene la posibilidad de establecer que la concesión de dicho beneficio en esas circunstancias es acorde con el objeto y propósito de las proposiciones relevantes del convenio (OCDE, 2017, p.589). Con base en lo anterior, la doctrina ha afirmado que es el contribuyente quien tiene la carga de probar el elemento objetivo para evitar que se aplique la РPт; de ahí que se afirme por parte de algunos autores que corresponde a la Administración Tributaria determinar razonablemente que el propósito principal de una operación es la obtención del beneficio tributario, en tanto que corresponde al contribuyente determinar que la concesión de ese beneficio no contraviene el propósito de las normas pertinentes del convenio.

Esta distribución de la carga de la prueba ha sido criticada por la doctrina, entre otras cosas, por el desequilibrio que se presenta en perjuicio del contribuyente respecto del estándar probatorio pues, si se tiene cuenta el texto de la PPT y lo establecido en los comentarios al MOCDE, la Administración Tributaria solo tendría que llegar a la conclusión razonable de que el propósito principal de la transacción fue la obtención de uno o varios beneficios concedidos por un CDI, mientras que el contribuyente, para lograr la no aplicación de la PPT, deberá determinar o, en otras palabras, establecer la correspondencia entre la concesión del beneficio y el objeto y propósito del tratado.

En ese sentido, autores como Michael Lang (2014) han afirmado que, si bien la Autoridad Tributaria tiene la obligación de probar el elemento subjetivo de la PPT, "los requisitos no son demasiado exigentes: deben ser meramente razonables, pero no, por ejemplo, convincentes" (p. 658). Sin embargo, es necesario anotar que, independientemente del estándar probatorio exigido en cada caso, los dos elementos contienen un alto grado de ambigüedad, lo cual implica que la prueba de ambos no podrá exceder de lo meramente razonable y que del texto de la PPT no se infiere que sea deber del contribuyente probar el elemento objetivo de la regla.

Ahora bien, en relación con la carga de la prueba, es necesario diferenciar entre las cuestiones de hecho, referidas a los sucesos o circunstancias y las de Derecho, referidas a las normas. Así, en tratándose del elemento subjetivo de la PPT, es decir, del análisis objetivo que debe realizarse para concluir razonablemente que la obtención de un beneficio tributario es uno de los propósitos principales de la operación, se comparte la opinión de autores como Blazej Kuzniacki (2018), quien afirma que, en estos casos, al tratarse de cuestiones de hecho, la carga de la prueba está en cabeza de la Administración y del contribuyente en la medida en que, en un primer momento, es la Autoridad Tributaria la que debe demostrar la configuración del elemento subjetivo de la PPT para que, en un momento posterior, el contribuyente pueda aportar el material probatorio pertinente que desvirtúe la conclusión de la Administración. El mencionado autor señala:

En este sentido, la carga de la prueba no recae en las autoridades tributarias ni en el contribuyente, sino que se divide entre ellas: las autoridades tributarias deben realizar el primer movimiento reuniendo y demostrando evidencia de que uno de los principales 
propósitos del acuerdo o transacción del contribuyente era obtener un beneficio del tratado; el contribuyente debe entonces contrarrestar lo anterior reuniendo evidencia y demostrando evidencia para demostrar el Estado opuesto de los asuntos (ej. la existencia de sustancia económica y propósitos comerciales distintos de la evasión fiscal). Por lo tanto, si las autoridades fiscales no tienen ninguna indicación de que uno de los propósitos principales fuera obtener los beneficios del tratado, no habrá razón para aplicar el PPT y los contribuyentes no tendrán que defenderse. En este sentido, la carga de la prueba recae esencialmente en las autoridades fiscales (Kuzniacki, 2018, p. 248).

Además, siguiendo a autores como Andrés Báez (2016), aspectos como la existencia, la interpretación y el propósito de una disposición jurídica son aspectos respecto de los cuales no puede aplicarse la carga de la prueba, toda vez que, como se mencionó anteriormente, solo son objeto de prueba las cuestiones de hecho, por lo que

(...) cualquiera que sea la formulación del elemento objetivo (como un requisito más del test antiabuso o, como en la PPT, como una posibilidad para contrarrestar la concurrencia del elemento subjetivo antes descrito), corresponde a la Administración y, en su actividad revisora, a los tribunales, determinar si la obtención de un beneficio convencional es o no conforme a la finalidad de las normas relevantes de un CDI. En resumidas cuentas, la Administración cuenta con la potestad (y con el deber) de determinar si la obtención de un beneficio convencional como consecuencia de un negocio realizado con el propósito esénciela de obtener tales beneficios es o no conforme a la finalidad de las disposiciones que recoge tal beneficio. (Báez, 2016, p. 23).

\section{Efectos}

Analizados el ámbito de aplicación y la estructura de la PPT, conviene ahora estudiar los efectos derivados de su aplicación. En ese sentido, hay que mencionar que, de la lectura del texto de la regla, la única consecuencia jurídica que se deriva de la verificación de su supuesto de hecho es la no concesión de los beneficios contemplados en el CDI. En efecto, el texto de la PPT solo menciona que, de verificarse el supuesto de hecho, es decir que, en caso de que la Administración Tributaria llegue a la conclusión razonable de que uno de los propósitos principales de un acuerdo u operación era la obtención de un beneficio tributario reconocido por un CDI, podrá negar la concesión de dichos beneficios.

Sin embargo, ni la norma ni los comentarios realizados a la misma por la oCDE mencionan otras consecuencias derivadas de su aplicación, surgiendo, de esa manera, interrogantes respecto de la situación del contribuyente en un momento posterior a la aplicación de la PPT como, por ejemplo, ¿debe reestructurarse la operación o transacción ejecutada por el contribuyente por una considerada como ajustada a los fines del CDI? Y, de ser así, ¿podría el contribuyente acceder a los beneficios reconocidos por el CDI para este tipo de operaciones? o ¿qué efecto debe tener la aplicación de la PPT en el otro Estado contratante? 
$\mathrm{Al}$ respecto, es necesario tener en cuenta que el MLI contempla la posibilidad de que los Estados incluyan en sus CDI una cláusula en virtud de la cual, a pesar de haber negado la concesión de los beneficios tributarios en aplicación de la PPT, la autoridad competente pueda concederlos al contribuyente cuando considere que, de no haberse realizado el negocio abusivo, el reconocimiento de los mismos hubiese resultado procedente; en ese sentido, el artículo 7(4) del MLI dispone:

Cuando se deniegue a una persona la aplicación de un beneficio previsto en un Convenio fiscal comprendido en virtud de disposiciones en él incluidas (como puedan resultar modificadas por este Convenio que denieguen total o parcialmente la concesión de los beneficios si el propósito o uno de los propósitos principales de un acuerdo u operación, o de alguna de las personas relacionadas con un acuerdo u operación, fuera el de obtener dichos beneficios, la autoridad competente de la Jurisdicción contratante que en ausencia de dichas disposiciones hubiera concedido el beneficio tratará no obstante a esa persona como legitimada para la obtención del mismo, o de otros beneficios en relación con un determinado elemento de renta o de patrimonio, si dicha autoridad competente, a instancia de esa persona y tras haber considerado los hechos y circunstancias oportunos, determina que esa persona hubiera obtenido los beneficios aún sin mediar tal operación o acuerdo.

Por su parte, la doctrina ha considerado que en los casos en los que se niegue la concesión de beneficios tributarios derivados de la ejecución de una operación o transacción determinada, en virtud de la aplicación de la PPT, las consecuencias fiscales de esa operación o transacción deberán ser determinadas atendiendo la sustancia económica de la mismas y las normas que resultarían aplicables si el negocio se hubiese realizado de conformidad con el fin del tratado ${ }^{20}$.

Esta posición resulta acertada pues, de lo contrario, la simple negativa de los beneficios por parte de la autoridad tributaria podría resultar en lo que la doctrina ha denominado el "efecto penalizador de la PPT", esto es, en que se sometería a los contribuyentes que intervinieron en la ejecución de una transacción abusiva a cargas adicionales a las que les hubiese correspondido de haber realizado negocios no abusivos lo cual, en últimas, desdibujaría la finalidad de una cláusula general anti-abuso pues:

(...) pierde de vista que la finalidad de cualquier cláusula anti-abuso no puede ser la imposición de cargas tributarias adicionales a los contribuyentes que acometen negocios abusivos sino, exclusivamente, la imposición de un nivel de tributación igual al que se hubiera producido de no haberse acometido tales negocios abusivos (Báez, 2016, p. 41). 
Todo lo anterior, sumado a la amplia discrecionalidad otorgada por la PPT a las Autoridades Tributarias no solo en lo relacionado con la aplicación de la regla sino también en lo que respecta a la determinación de sus consecuencias, hace que la regla del propósito principal, de la manera en la que fue redactada en el MLI, tenga un alto grado de inseguridad jurídica, lo cual afecta los derechos e intereses de los contribuyentes y, en últimas, desdibuja la finalidad última de los Convenios para evitar la Doble Imposición que, como se ha mencionado en repetidas ocasiones, es el fomento del comercio internacional; es por esto que, teniendo en cuenta que la PPT una herramienta muy útil a la hora de combatir contra las operaciones abusivas de los contribuyentes, resulta indispensable que en la aplicación de la PPT se recurra a criterios objetivos como, por ejemplo, que la creación de una sociedad en otro Estado responda a criterios económicos y que dicha sociedad efectivamente realice actividades económicas en el Estado en el que fue creada, los cuales permitan que reduzcan la discrecionalidad de las autoridades tributarias a la hora de aplicar la regla y de una mayor certeza a los contribuyentes en la selección de los caminos adecuados para lograr sus objetivos económicos y financieros, pues "sin seguridad jurídica frente al ámbito de aplicación y alcance del derecho tributario, la promesa de mayor inversión y negocios que inspira la suscripción de un CDI puede esfumarse con facilidad" (Gómez, 2018, p. 27).

\section{Interacción de la PPT con otras normas anti-abuso}

Por último, conviene analizar la interacción de la regla de propósito principal con otras normas tanto internacionales como domésticas. A este respecto, hay que mencionar que, si bien en los comentarios al Modelo de Convenio de la OCDE se incluyó desde hace algún tiempo la figura del guiding principle, fue solo con el Plan de Acción BEPS y, en especial, con el MLi que se incluyó en el articulado del Modelo una cláusula general anti-abuso en la forma de la PPT la cual, en ese orden de ideas, tiene fuerza vinculante en la medida en que los Estados decidan incluirla en sus CDI.

Lo anterior, sumado a que, tal y como ya se mencionó, en la Acción 6 y en el Instrumento Multilateral se propone no solo la inclusión de la PPT en el texto de los CDI, sino que, además, se plantea la inserción de otras disposiciones como una Cláusula de Limitación de Beneficios, da lugar a que surjan diferentes cuestionamientos relacionados con la interacción de la regla del propósito principal con otras disposiciones del tratado e, incluso, con disposiciones de carácter doméstico.

En cuanto a la interacción de la PPT con otras disposiciones del convenio y, en especial con la cláusula de limitación de beneficios, en primer lugar, es necesario mencionar que, tal y como lo afirma Andrés Báez (2016), gran parte de la Acción 6 se centra en el diseño, la interpretación y la incorporación en el Modelo oCDE de la cláusula de limitación de beneficios utilizada principalmente en los CDI suscritos siguiendo el Modelo de los Estados Unidos, la cual siguiendo lo establecido en el Instrumento Multilateral puede ser implementada conjuntamente con la PPT. 
Así las cosas, las relaciones que pueden surgir entre la LOB y la PPT podrían resumirse en dos casos, a saber: i) casos en los que la regla del propósito principal no es aplicable a situaciones en las que se niegue la concesión de beneficios en virtud de la LOB y ii) eventos en los que, en aplicación de la PPT, se niegan beneficios concedidos de conformidad con la cláusula de limitación de beneficios.

En el primer supuesto, esto es, los casos en los que la regla del propósito principal no es aplicable a situaciones en las que se niegue la concesión de beneficios en virtud de la LOB, se está frente a un típico ejemplo de la aplicación del principio interpretativo según el cual la ley especial prima sobre la ley general, toda vez que la inoperancia de la PPT se deriva de la inexistencia de un beneficio, pues este ha sido previamente negado por la LOB.

Así, piénsese, por ejemplo, en una compañía residente en un Estado contratante, pero cuyas acciones son propiedad, exclusivamente, de otra sociedad residente en un tercer Estado que no cuenta con un CDI suscrito con el Estado de la fuente; en este caso, si de acuerdo con las disposiciones de la cláusula de limitación de beneficios un residente de un Estado no pueda ser catalogado como una "persona calificada" en razón a que determinado porcentaje de su capital es propiedad de un residente de un tercer Estado, procedería la denegación de los beneficios sin tener que acudir a la aplicación de la PPT.

Ahora, en el segundo supuesto, es decir en aquellos eventos en los que, en aplicación de la PPT, se niegan beneficios concedidos de conformidad con la cláusula de limitación de beneficios el informe final de la Acción 6, menciona que

(...) el hecho de que un contribuyente tenga derecho a los beneficios del convenio de acuerdo con los párrafos 1 a 6 [LOB] no significa que esos beneficios no puedan denegarse de acuerdo con el párrafo 7 [РРТ]. Los párrafos 1 a 6 son reglas que se centran en la naturaleza jurídica, la estructura de propiedad y en las actividades de un residente en un Estado contratante, lo cual no implica que una transacción realizada por uno de esos residentes no pueda constituir un uso indebido del convenio (OCDE, 2016, p. 55-56).

A manera de ejemplo, el informe final de la acción 6 propone el caso de A, una sociedad residente en el Estado A que pretende invertir en títulos de renta fija emitidos por una sociedad residente en el Estado B. A y B no han suscrito un CDI. C es una entidad financiera que cotiza en un mercado regulado del Estado C, que sí tiene suscrito un CDI con el Estado $\mathrm{B}$, convenio que cuenta con una LOB y además incorpora una cláusula PPT. El banco suscribe un contrato financiero con $\mathrm{A}$, en virtud del cual invertirá en los títulos de renta fija emitidos por la entidad residente en B, pagando posteriormente los intereses cobrados a A, detraída la correspondiente comisión con la intención de que A se beneficie del trato más favorable del CDI. Como consecuencia de ello, los intereses pagados por B al banco no se verán sujetos a los tipos de retención recogidos en el derecho doméstico de B (del $21 \%$ ), sino al tope máximo de retención previsto en el artículo 11 del CDI entre B y C $(10 \%)^{21}$. 
Figura 2. Caso en el QUe Los beneficios ConCedidos En Virtud DE UNA LOB SON NEGADOS EN APLICACIÓN DE LA PPT

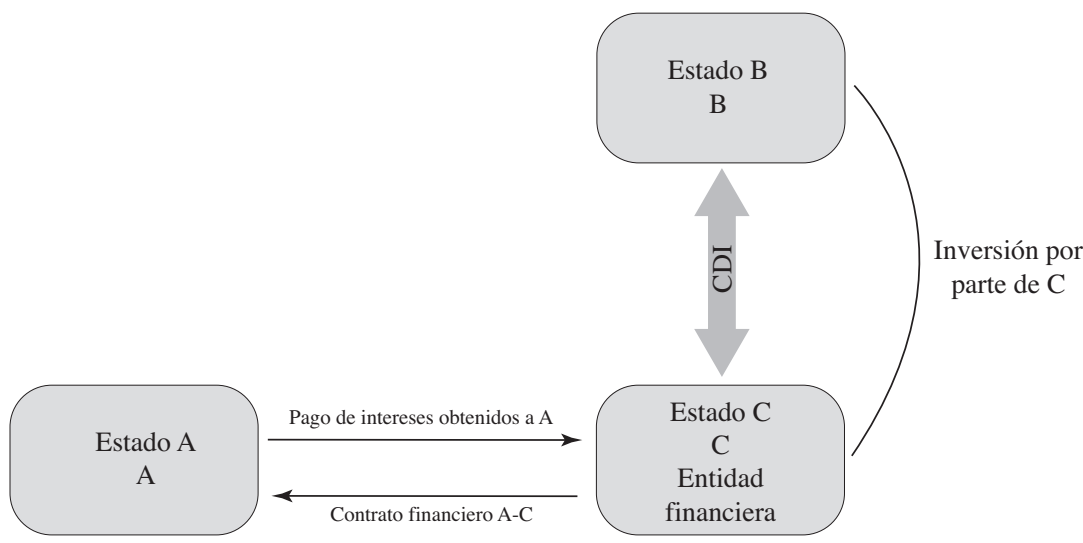

Fuente: Elaboración propia.

En este caso, si bien la sociedad C puede acceder legítimamente a los beneficios del tratado suscrito entre los Estados B y C toda vez que, de acuerdo con la LOB, al ser una persona residente de uno de los Estados contratantes que cotiza regularmente en un mercado de valores reconocido, puede ser considerada como una "persona calificada", la no concesión de los beneficios del convenio resultaría procedente en aplicación de la PPT teniendo en cuenta que las operaciones realizadas por $\mathrm{C}$ tienen como finalidad beneficiar indirectamente a la compañía A, residente de un tercer Estado.

Bajo ese entendido, siguiendo a Andrés Báez (2016), en estos casos es evidente que el principio lex specialis no aplicaciones aplicable, pues no nos enfrentamos a un caso en el que se deba preferir la aplicación de una de las dos normas (la LOB y la PPT), sino que se trata de dos normas que se aplican sucesivamente.

Así las cosas, podría afirmarse que la interacción entre la LOB y la PPT no presenta inconveniente alguno pues, en los supuestos mencionados, la aplicación de una o ambas normas dependerá de que, en determinado supuesto de hecho, se presente alguno de los elementos distintivos de cada una, o sea, la inexistencia de una persona calificada, en tratándose de la Lов о la ausencia del propósito principal de obtener una ventaja tributaria, respecto de la PPT. En ese orden de ideas, en el supuesto de que un contribuyente que cumpla con las condiciones establecidas en una cláusula de limitación de beneficios y, en consecuencia, tenga la calidad de "persona calificada" pero que realice una transacción con el único propósito de obtener los beneficios tributarios contendidos en un CDI, se deberán conceder los beneficios fiscales en virtud de la LOB, pero, al mismo tiempo, deberán ser denegados en virtud de la PPT.

Sin embargo, autores como Pablo Hernández González-Barreda (2017) afirman que, teniendo en cuenta que las normas mencionan que su aplicación procede "sin perjuicio 
de las demás normas del convenio", a simple vista podría afirmarse que sus ámbitos de aplicación podrían llegar a superponerse y, en consecuencia, la no interferencia entre la regla del propósito principal y la cláusula de limitación de beneficios es aparente en la medida en que

Incluyendo tal reconocimiento al resto de normas del tratado como parte de la construcción de presupuesto de aplicación del beneficio fiscal previo a la norma antiabuso, ambas normas están reconociéndose y excepcionándose recíprocamente. De esa forma, la norma de propósito principal partiría del beneficio fiscal reconocido con carácter previo a la aplicación de la propia norma como parte de su presupuesto de hecho/ consecuencia, incluyendo la norma de limitación de beneficios como parte del presupuesto de hecho de ese beneficio fiscal; y la norma de limitación de beneficios partiría del hecho de ese beneficio fiscal determinado una vez superada la norma de propósito principal y con carácter previo a la propia aplicación del carácter de sujeto cualificado (Hernández, 2017,p. 180).

Sin embargo, es necesario afirmar que independientemente de la incidencia que ambas normas puedan tener en un mismo supuesto de hecho, cada una tiene su propio ámbito de aplicación, pues la cláusula de limitación de beneficios, tal y como ya se mencionó, incluye las reglas que se centran en la naturaleza jurídica, la estructura de propiedad y en las actividades de un residente en un Estado contratante mientras que la cláusula del propósito principal se centra en la finalidad del contribuyente en la realización de determinada transacción por lo que, en lugar de ser contrarias, la aplicación de estas normas es complementaria y su inclusión en los CDI es adecuada para la consecución de los fines perseguidos por el Plan de Acción.

En efecto, en el Informe Final de la Acción 6 la OCDE reconoce que la LOB y la PPT antes de ser contradictorias son complementarias en la medida en que

(...) algunas de las disposiciones de la CLB se basan en criterios objetivos, proporcionando una seguridad jurídica mayor a la que le puede ofrecer la NPP que, por el contrario, supone realizar un análisis caso por caso a fin de valorar qué podemos entender como uno de los principales propósitos de una operación o acuerdo (OCDE, 2015,p. 19).

Ahora bien, respecto de la interacción con las normas anti-abuso domésticas, en el informe final de la Acción 6 se establece que las normas domésticas de los Estados contratantes serán aplicables en tres supuestos, a saber: i) la remisión expresa de las disposiciones del convenio a las normas de derecho doméstico, ii) la coincidencia de la norma interna con los principios generales anti-abuso o con el texto de la PPT y iii) que las reglas anti-abuso domésticas formen parte de los instrumentos de interpretación de las disposiciones convencionales. Bajo ese entendido, en estos casos no se presentaría conflicto alguno entre las normas convencionales y domésticas, pues los efectos de estas se estarían produciendo 
en virtud de la aplicación directa del convenio, la cual ha sido avalada por la ocDE que, en el informe final de la Acción 6, reconoce que en los supuestos de uso abusivo de los Convenios para evitar la Doble Imposición en los que una persona trata de eludir las normas tributarias internas utilizando los beneficios del convenio, considerando que la norma que pretende eludirse es una norma interna, "la solución vendría de la mano de normas anti-abuso internas y no únicamente convencionales" (OCDE, 2015, p. 17).

Sin embargo, teniendo en cuenta que en algunos ordenamientos como, por ejemplo, en el colombiano, las normas de Derecho internacional deben ser incorporadas al Derecho interno quedando, de esta manera, en el mismo nivel de las normas domésticas, los problemas surgirían cuando una norma doméstica, como una cláusula general anti-abuso y una norma convencional, la cláusula de propósito principal, previeran para un mismo supuesto de hecho consecuencias incompatibles.

En estos casos, para determinar la norma aplicable se deberá tener en cuenta la perspectiva que tenga cada Estado respecto de las relaciones entre el Derecho internacional y el Derecho doméstico. Así, el conflicto solo se presentará en los casos en los que la norma convencional y la norma doméstica se encuentren al mismo nivel, para cuya solución se deberá acudir a los principios generales de interpretación en el análisis de cada caso concreto, en particular, el de la lex specialis.

\section{La aplicación de la PPT en los Convenios para evitar la Doble Imposición suscritos por Colombia ${ }^{22}$}

\section{A. Medidas para evitar el uso abusivo de los Convenios para evitar la Doble Imposición en los CDI suscritos por Colombia}

En la actualidad, el Estado colombiano cuenta con una red de Convenios para evitar la Doble Imposición compuesta por 13 tratados suscritos con otros Estados, de los cuales 9 se encuentran actualmente vigentes, uno está a la espera de la ratificación por parte del otro Estado contratante para entrar en vigor y los 3 restantes están en proceso de ratificación.

Ahora bien, es necesario tener en cuenta que la introducción de medidas tendientes a evitar el uso abusivo de los tratados por parte de los contribuyentes varía dependiendo del momento de suscripción del tratado, más cuando la mayor parte de estos fueron suscritos con anterioridad al Plan de Acción BEPs. No obstante, en los Convenios para evitar la Doble Imposición suscritos por el Estado colombiano se pueden encontrar incluidas las medidas previstas en la Acción 6 del Plan de Acción, es decir, la mención expresa en el preámbulo de los tratados, la cláusula de propósito principal y/o la cláusula limitativa de beneficios las cuales, sin embargo, tal y como se verá más adelante, en algunas ocasiones

22 El análisis se realizó con base en los documentos de notificaciones y reservas depositados por los Estados contratantes al momento de la suscripción del MLI, en los que consta la posición adoptada por cada Estado a 4 de diciembre de 2018 . 
estas medidas, en la manera en que se encuentran contempladas en el texto de los tratados, no cumplen con los estándares establecidos por el Plan de Acción.

Lo anterior puede resumirse en la siguiente tabla:

Tabla 3. Resumen de los CDI Vigentes suscritos Por Colombia

\begin{tabular}{|c|c|c|c|c|c|}
\hline País & Ratificado & Vigencia & Preámbulo & PPT & LOB \\
\hline España & $\begin{array}{l}\text { X } \\
\text { (Ley } 1082 \text { de 2006) }\end{array}$ & $\begin{array}{l}23 \text { de octubre de } \\
2008\end{array}$ & $\begin{array}{l}\text { X (no en los términos de la } \\
\text { Acción 6) }\end{array}$ & - & - \\
\hline Chile & \begin{tabular}{|l}
$\mathrm{X}$ \\
$($ Ley 1261 de 2008) \\
\end{tabular} & $\begin{array}{l}22 \text { de diciembre de } \\
2009\end{array}$ & $\begin{array}{l}\text { X (no en los términos de la } \\
\text { Acción 6) }\end{array}$ & $\mathrm{X}$ & $\mathrm{X}$ \\
\hline Suiza & $\begin{array}{l}\text { X } \\
\text { (Ley } 1344 \text { de 2009) } \\
\end{array}$ & 1 de enero de 2012 & - & $\mathrm{X}$ & - \\
\hline Canadá & $\begin{array}{l}\text { X } \\
(\text { Ley } 1459 \text { de 2011) }\end{array}$ & 12 de junio de 2012 & $\begin{array}{l}\text { X (no en los términos de la } \\
\text { Acción 6) }\end{array}$ & $\mathrm{X}$ & - \\
\hline México & $\begin{array}{l}\text { X } \\
\text { (Ley } 1568 \text { de 2012) } \\
\end{array}$ & 11 de julio de 2013 & $\begin{array}{l}\text { X (no en los términos de la } \\
\text { Acción 6) }\end{array}$ & $\mathrm{X}$ & $\mathrm{X}$ \\
\hline República de Corea & $\begin{array}{l}\text { X } \\
\text { (Ley } 1667 \text { de 2013) } \\
\end{array}$ & 3 de julio de 2014 & $\begin{array}{l}\text { X (no en los términos de la } \\
\text { Acción 6) }\end{array}$ & $\mathrm{X}$ & - \\
\hline Portugal & \begin{tabular}{|l} 
X \\
(Ley 1692 de 2013) \\
\end{tabular} & 30 de enero de 2015 & $\begin{array}{l}\text { X (no en los términos de la } \\
\text { Acción 6) }\end{array}$ & $\mathrm{X}$ & - \\
\hline India & $\begin{array}{l}\text { X } \\
\text { (Ley } 1668 \text { de 2013) } \\
\end{array}$ & 7 de julio de 2014 & $\begin{array}{l}\text { X (no en los términos de la } \\
\text { Acción 6) }\end{array}$ & $\mathrm{X}$ & - \\
\hline República Checa & $\begin{array}{l}\text { X } \\
\text { (Ley } 1690 \text { de 2013) } \\
\end{array}$ & 6 de mayo de 2015 & $\begin{array}{l}\text { X (no en los términos de la } \\
\text { Acción 6) }\end{array}$ & $\mathrm{X}$ & - \\
\hline Francia & En proceso de ratificación & - & $\mathrm{X}$ & $\mathrm{X}$ & - \\
\hline Reino Unido & $\begin{array}{l}\text { X } \\
\text { (Ley } 1939 \text { de 2018) } \\
\end{array}$ & - & $X$ & - & - \\
\hline Emiratos Árabes & En proceso de ratificación & - & $\mathrm{X}$ & $\mathrm{X}$ & $\mathrm{X}$ \\
\hline Italia & En proceso de ratificación & - & $\mathrm{X}$ & $\mathrm{X}$ & - \\
\hline Japón & En proceso de ratificación & - & $\mathrm{X}$ & $\mathrm{X}$ & $\mathrm{X}$ \\
\hline
\end{tabular}

Fuente: Elaboración propia, realizada con base en la información del sitio web de la Cancillería (http://apw.cancilleria. gov.co/tratados/SitePages/BuscadorTratados.aspx?TemaId=41\&Tipo=B)

Con base en lo anterior, para realizar el análisis sobre la aplicación de la PPT, de la manera en que fue redactada en el MLI, se agruparán los Convenios para evitar la Doble Imposición suscritos por Colombia en tres grupos, a saber: i) aquellos que incluyen la PPT cumpliendo con los estándares del Plan de Acción; ii) aquellos que, no obstante incluir una cláusula de propósito principal, esta no cumple con los estándares del Plan de Acción, y iii) aquellos que no incluyen una cláusula de este tipo ${ }^{23}$.

23 Si bien los convenios suscritos con Reino Unido, los Emiratos Árabes e Italia no fueron incluidos como convenios cubiertos al momento de la firma del MLI, serán estudiados de todas maneras teniendo en cuenta que podrán ser incluidos al momento del depósito del instrumento de ratificación. 


\section{B. Convenios que incluyen una PPT de acuerdo con los estándares del Plan de Acción}

En este grupo, en el que se incluyen los CDI suscritos por Colombia con Francia, Emiratos Árabes e Italia, la cláusula de propósito principal incluida en el texto de los tratados está redactada en los mismos términos en los que fue contemplada en el Instrumento Multilateral.

En efecto, en los artículos 26 del cDi suscrito con Francia, el 22 del Convenio suscrito con los Emiratos Árabes, el 29 del CDI celebrado con Italia y el 28(8) del Convenio Colombia-Japón se incluye una cláusula de propósito principal redactada en los siguientes términos:

No obstante las demás disposiciones del Convenio, los beneficios concedidos en virtud del presente Convenio no se otorgarán respecto de un elemento de renta cuando sea razonable concluir, teniendo en cuenta todos los hechos y circunstancias pertinentes, que el acuerdo u operación que directa o indirectamente genera el derecho a percibir ese beneficio tiene entre sus propósitos principales la obtención del mismo, a menos que se establezca que otorgar el beneficio en esas circunstancias habría Estado de acuerdo con el objeto y propósito de las disposiciones pertinentes de este Convenio.

En ese orden de ideas, la implementación de la PPT en estos convenios no presenta inconveniente alguno, pues las disposiciones mencionadas cumplen con los estándares fijados por la acción 6 y por MLI, habida cuenta de que la disposición es idéntica a aquella incluida en el Instrumento multilateral, por lo que no habría necesidad de aplicar las disposiciones consagradas en dicho instrumento si se tiene en cuenta que, como ya se mencionó, están encaminadas a modificar o reemplazar las disposiciones de los convenios que no se ajusten a los términos contemplados en el MLI.

A manera de ejemplo, el artículo 28(8) del cDI suscrito entre Colombia y Japón dispone:

Sin perjuicio de las demás disposiciones del presente Convenio, no se otorgará un beneficio en virtud del Convenio con respecto a una partida de renta si es razonable concluir, teniendo en cuenta todos los hechos y circunstancias pertinentes, que la obtención de ese beneficio fue uno de los principales propósitos de cualquier arreglo o transacción que resulte directa o indirectamente en ese beneficio, a menos que se establezca que otorgar ese beneficio en estas circunstancias estaría de acuerdo con el objeto y el propósito de las disposiciones pertinentes del Convenio.

Lo anterior sin perjuicio de que, tal como se deduce de la posición adoptada por el Estado colombiano al momento de la suscripción del MLI, los Estados puedan adelantar la negociación tendiente a incluir en sus convenios una cláusula de limitación de 
beneficios que complemente la PPT con la finalidad de dotar de herramientas adicionales a las autoridades tributarias para combatir los supuestos de uso abusivo de los convenios de doble imposición si se tiene que cuenta que cada norma tiene su propio ámbito de aplicación, pues la LOB se centra en la criterios objetivos mientras que la PPT analiza la finalidad del contribuyente en la realización de determinada transacción, por lo que su inclusión en los CDI es adecuada para la consecución de los fines perseguidos por el Plan de Acción.

\section{Convenios que incluyen una PPT que no cumple con los estándares del Plan de Acción}

En este grupo, en el que está la mayor parte de los CDI suscritos por el Estado colombiano, si bien se incluye una cláusula de propósito principal, esta no se ajusta, por diversas razones, a las recomendaciones de la Acción 6 ni a las disposiciones del MLI.

En primer lugar, el numeral 3 del artículo 27 del Convenio Colombia-Chile, el numeral 1 del artículo 26 del CDi Colombia-Canadá y el numeral 1 del artículo 26 del Convenio Colombia-Corea, limitan la aplicación de la cláusula de propósito principal a la no concesión de beneficios relacionados con los artículos 10, 11 y 12 del Convenio, es decir, a los relativos a los dividendos, intereses y regalías.

Por su parte, en el Convenio Colombia-México, si bien se incluye una cláusula de propósito principal en el numeral 2 del artículo 26, esta disposición se inserta dentro de la regulación de una cláusula de limitación de beneficios como una excepción a la regla principal de manera que, las personas que no cumplan con las condiciones establecidas en el numeral primero del citado artículo podrán acceder a los beneficios del convenio siempre que demuestren que las operaciones no tuvieron como propósito principal la obtención de dichos beneficios lo cual termina limitando la aplicabilidad de la PPT.

En ese orden de ideas, al circunscribir el ámbito de aplicación de la PPT a ciertas disposiciones del convenio, dichas cláusulas no cumplen con los fines buscados por la Acción 6 que, además de pretender abarcar el mayor número de hipótesis en que se pueda presentar el uso abusivo de los convenios, consiste en evitar la concesión, en situaciones inapropiadas, de cualquier beneficio contemplado en el tratado, entendiendo por tal, la situación más favorable del contribuyente generada por la aplicación de las normas de derecho interno o de otras normas del tratado.

En segundo lugar, el artículo 25 del Convenio Colombia-República Checa dispone:

No obstante las disposiciones de cualquier otro Artículo de este Acuerdo, los beneficios que este Acuerdo contempla no serán otorgados a sociedades de cualquier Estado contratante si el propósito de dichas sociedades es obtener beneficios en virtud de este Acuerdo que de otra manera no estarían disponibles (Ley 1667, 2013, art. 25). 
Por su parte, el artículo 28 del CDI Colombia-India establece:

Una empresa de un Estado Contratante no tendrá derecho a los beneficios de este Acuerdo si el principal propósito de Ia creación de dicha empresa fue la de obtener los beneficios de este Acuerdo que de otra forma no estarían disponibles (Ley 1668, 2013, art. 28).

Las disposiciones citadas, además de limitar la aplicación de la PPT a la creación de empresas o sociedades con la finalidad de obtener los beneficios del convenio, establecen que la obtención de los beneficios debe ser el propósito principal de la operación lo cual riñe con la forma en la que fue prevista la PPT en la Acción 6 y en el MLI, de acuerdo con la cual la concesión de los beneficios debe ser el propósito principal o uno de los propósitos principales de la operación.

Así las cosas, teniendo en cuenta que en los tratados mencionados las cláusulas de propósito principal no están redactadas en los términos del MLI, estas deberán ser modificadas o reemplazadas por la PPT del Instrumento Multilateral siguiendo las reglas y opciones previstas en el instrumento.

Del análisis de los escritos de reservas y notificación depositado por cada Estado parte del MLI al momento de su suscripción se pueden realizar las siguientes consideraciones.

En primer lugar, es necesario indicar que los CDI mencionados anteriormente fueron incluidos como convenios comprendidos por los Estados Contratantes, por lo que las disposiciones del MLI surtirán plenos efectos frente a las disposiciones de dichos convenios, salvo las disposiciones que al respecto realicen los Estados.

En segundo lugar, se observa que ninguno de los Estados mencionados realizó la reserva del artículo 7(15)(a), es decir que ninguno optó por la realización de una negociación directa con su contraparte, con la finalidad de implementar una cláusula detallada de limitación de beneficios o una manera diferente de cumplir con el estándar mínimo contemplado por la Acción 6 y, de la misma manera, tampoco realizaron la reserva prevista en el artículo 7(15)(b) lo cual significa que, a juicio de los Estados, en el texto los convenios no existe una cláusula de propósito principal que se ajuste a los términos de la PPT contemplada en el MLI.

De conformidad con lo anterior, los Estados realizaron la notificación prevista en el artículo 7(17)(a) del MLI siendo coincidentes las disposiciones indicadas por el Estado Colombiano y los Estados de Chile, Canadá, Corea, República Checa, India y Portugal. Así las cosas, respecto de estos Convenios, la PPT en los términos en los que fue redactada en el MLI reemplazará las disposiciones indicadas por los Estados una vez entre en vigor, lo cual sucederá el primer día del mes siguiente al vencimiento del plazo de tres meses contados a partir del depósito del instrumento de ratificación ${ }^{24}$.

24 Respecto de Chile y Canadá surge la obligación adicional de adelantar la negociación directa de una lob detallada pues, junto con Colombia, estos Estados optaron por la aplicación provisional de la PPT. 
Ahora bien, en relación con el Convenio Colombia-México, resulta pertinente mencionar que si bien los dos Estados incluyeron el CDI como Convenio Comprendido, en la notificación de que trata el artículo 7(17)(a) no se hizo mención, por parte de ninguno de los Estados contratantes, de disposición alguna que incluyera una PPT en el texto del tratado, por lo que, en atención a que tampoco ninguno de los Estados realizó reserva alguna tendiente a limitar la aplicación de la PPT contenida en el Instrumento Multilateral, esta cláusula será automáticamente incluida en los convenios, de acuerdo con el artículo 7(2) del MLI, el cual dispone que la PPT se aplicará en sustitución o en ausencia de una norma que cumpla la misma función. Ahora bien, sobre este punto, hay que tener en cuenta que tanto México como Colombia optaron por la aplicación de la LOB simplificada contenida en el Instrumento Multilateral y que, además, Colombia decidió aplicar la PPT de manera provisional mientras adelanta la negociación directa tendiente a implementar una LoB detallada que reemplace o complemente la PPT.

\section{El Convenio Colombia-Suiza}

En este análisis, merece una mención especial el cDI suscrito por Colombia con Suiza. Este Convenio y su correspondiente Protocolo fueron suscritos por los Estados contratantes en Berna el 26 de octubre de 2007, por lo que su contenido no incluye las recomendaciones del Plan de Acción BEPS.

En efecto, para lo que interesa a este trabajo es necesario tener en cuenta que el artículo 21 del Convenio, relativo a la cláusula anti-abuso, dispone:

1. Cuando una sociedad residente en un Estado Contratante recibe una renta proveniente del otro Estado Contratante y transmite, directa o indirectamente, en cualquier momento y bajo cualquier forma, al menos la mitad de esta renta a una o más personas que no son residentes de este otro Estado Contratante, este elemento de renta no beneficia del presente Convenio.

2. Las estipulaciones del apartado 1 de este artículo no son aplicables cuando la sociedad que procura la obtención de beneficios convencionales demuestre que las operaciones en causa no tienen como propósito principal la obtención de beneficios de este Convenio. La condición anterior se considera cumplida cuando el elemento de renta:

a) Es transmitido por la sociedad residente de un Estado Contratante a una o más personas que no son vinculadas a la sociedad; o

b) Beneficia de un tratamiento convencional equivalente o más favorable si esta hubiese estado recibida directamente por la o las personas a las cuales esta fue transmitida (Ley 1344, 2009, art. 21).

Así, del texto antes transcrito se observa que en este caso la aplicación de la PPT se encuentra concebida como una excepción a la regla anti-abuso contenida en el convenio de manera que el contribuyente pueda acceder a sus beneficios probando que el propósito 
principal de este no era el obtener dichos beneficios acreditando alguna de las dos situaciones mencionadas en la norma; lo anterior, como se puso de presente en el análisis de los otros convenios, no se ajusta a las recomendaciones del Plan de Acción y, en especial, de la Acción 6.

Sin embargo, en este punto, hay que tener en cuenta que Suiza, en el documento de notificaciones y reservas depositado al momento de la suscripción del MLI, no incluyó el convenio celebrado con Colombia como convenio comprendido.

Sobre este punto, resulta pertinente recordar que el MLI solo es aplicable respecto de los Convenios Comprendidos, entendiendo por tales, de acuerdo con el artículo 2 del Instrumento Multilateral, aquellos Convenios para evitar la Doble Imposición en materia de impuesto sobre la renta que estén en vigor entre dos o más partes y respecto de los cuales cada uno de los Estados contratantes haya notificado su inclusión como un convenio que se busca que sea modificado por el MLI. Así las cosas, en ausencia de la manifestación de la intención de una de las partes del CDI de incluir el tratado dentro de los convenios a ser modificados por el MLI, no se puede considerar dicho CDI como un convenio comprendido y, en consecuencia, las disposiciones del MLi no surtirán efecto alguno respecto del Convenio Colombia-Suiza.

Lo anterior implicaría que, para implementar las recomendaciones del Plan de Acción, se deberá adelantar una negociación directa entre los dos Estados que, muy probablemente, no se llevará a cabo en condiciones de igualdad teniendo en cuenta las diferencias económicas existentes entre ambas partes. Además, la realización de una negociación directa conllevará una demora en la aplicación de las medidas recomendadas por la OCDE, a través del Plan de Acción BEPs, las cuales deben ser implementadas por los Estados, más aún cuando ambos hacen parte de la OCDE y están en el deber de acatar e implementar las recomendaciones propuestas por dicha organizción.

Lo anterior en la medida en que, si bien las recomendaciones de esa organización no son vinculantes para los Estados miembros, hay que considerar que, siguiendo a (Merino Jara, 2015), las recomendaciones de la OCDE buscan codificar una serie de parámetros uniformes a nivel internacional para que los países miembros y no miembros las adopten los cuales

(...) en diversas ocasiones reflejan el Estado del desarrollo de normas consuetudinarias o son la base de tratados futuros e incluso, por su propia naturaleza, en tanto generan expectativas de comportamiento, están regidos de alguna manera por el principio de la buena fe, lo que explica su utilidad y cumplimiento (Toro Huerta, 2006, p. 538).

En ese sentido, al ser reconocidas y aplicadas por un número considerable de Estados, que entienden dichas recomendaciones como prácticas necesarias y obligatorias en materia de tributación internacional, las recomendaciones de la OCDE terminan adquiriendo cierta fuerza vinculante toda vez que su inobservancia podría conllevar el uso eventual de contramedidas por parte de la oCDE o de los demás Estados miembros (Merino Jara, 2015). 
Además, hay que mencionar que el Estado Colombiano en los últimos años ha venido incorporando su derecho interno las recomendaciones de la ocDE relacionada con el Plan de Acción por lo que, siendo consecuente con esta posición, debería buscar que sus Convenios para evitar la Doble Imposición cumplieran con los estándares fijados en BEPS.

No obstante, para algunos autores, la no inclusión de todos los CDI dentro del ámbito de aplicación del MLI:

(...) brindará algo de consuelo a la comunidad de planificación fiscal: las jurisdicciones que logren mantener partes de sus redes de tratados fuera del alcance del MLI, al abrir un margen de maniobra bilateral, serán vistas como una ventaja competitiva sobre otras (Hatting, 2017, p. 7)

Empero, la negociación bilateral directa, ya sea porque el convenio no tiene la calidad de convenio comprendido o porque fue la opción escogida por el Estado, no se ajusta a una de los objetivos buscados por el Plan de Acción BEPs como es el de implementar de manera rápida, eficaz y coordinadas las recomendaciones propuestas.

\section{Convenios que no incluyen una PPT}

Dentro del último grupo se encuentran los CDI que no cuentan con una cláusula de propósito principal, a saber, los Convenios celebrados por Colombia con el Reino Unido y España.

En relación con el Convenio Colombia-España, teniendo en cuenta tanto Colombia como España incluyeron el Convenio como convenio comprendido por el MLI y que ninguno de los dos Estados realizó reserva alguna respecto de la aplicación de la PPT, esta disposición se incluirá automáticamente en el CDI pues, tal y como se mencionó en relación con el Convenio Colombia-México, esta cláusula aplica en sustitución o en ausencia de una norma que cumpla la misma función.

Lo mismos efectos se producirán respecto del Convenio Colombia-Reino Unido siempre que, al momento de depositar el instrumento de ratificación del MLI, ambos Estados incluyan este convenio como convenio comprendido.

\section{Conclusiones}

Del análisis anterior se pueden establecer las siguientes conclusiones:

1. La Cláusula de Propósito Principal per se y, de la manera como esta fue consagrada en el MLI, conlleva un alto grado de inseguridad jurídica, lo cual, en consecuencia, podría generar efectos no deseados en la economía.

Sobre este punto, resulta pertinente mencionar que la seguridad jurídica, entendida como la confiabilidad y previsibilidad del ordenamiento jurídico o, en otras palabras, como la expectativa del individuo de poder predecir la actuación del poder público en la 
aplicación de las normas, es un factor fundamental del desarrollo económico en la medida en que genera un entorno de confianza para el agente económico toda vez que este puede predecir, con una gran probabilidad de acierto, las consecuencias económicas de sus actuaciones y, de esa manera, tomar las decisiones que más se ajusten a sus negocios y propósitos.

En ese orden de ideas, se puede afirmar que la seguridad jurídica es un presupuesto indispensable para generar confianza en los agentes económicos la cual, a su vez, es un factor determinante a la hora de invertir y, en consecuencia, de generar desarrollo económico, toda vez que este depende en gran medida de un sistema normativo adecuado que genere una base sólida para el desarrollo de los negocios.

En efecto, uno de los factores que inciden en el grado de confianza y certeza que puedan tener los individuos en el ordenamiento jurídico es la existencia de un sistema normativo claro y previsible, pues de lo contrario se generaría un ambiente de incertidumbre que, en últimas, conllevaría el aumento de los costos de inversión. Es por esto que una norma como la PPT, cuyos criterios de aplicación son poco claros e implica un alto grado de subjetividad que puede ser usado arbitrariamente por la Administración, afecta la seguridad jurídica de los contribuyentes, quienes no tienen certeza de cuándo una de sus operaciones pueda ser considerada abusiva, más aun si se tiene en cuenta que la carga tributaria es un factor de gran importancia para las empresas a la hora de decidir si invierten o no en determinada jurisdicción.

Dicha incertidumbre generada por la PPT se ve agravada si se tiene en cuenta que basta con que la obtención de un beneficio sea uno de los propósitos principales de la transacción para que esta pueda ser catalogada como abusiva y que el estándar probatorio en cabeza de la Administración no es demasiado estricto pues, para que se puedan negar los beneficios de un CDI, es suficiente con que la autoridad tributaria pueda concluir razonablemente que el propósito de determinada operación era la obtención de un tratamiento tributario más favorable.

Lo anterior, en palabras de Fernando Vives (2013, p. 76), sería un obstáculo para el desenvolvimiento adecuado de la actividad económica de los Estados, pues podría "impedir que los operadores alcancen la necesaria certeza respecto a que los poderes públicos ejercitarán sus potestades en un marco legal suficientemente delimitado y dentro del cual no tengan cabida comportamientos arbitrarios o inesperados".

Sin embargo, hay que tener en cuenta que, a pesar de los efectos no deseables de la Cláusula de Propósito Principal, relacionados con la seguridad jurídica de los contribuyentes, esta cláusula es una medida adecuada para hacer frente al problema del uso abusivo de los convenios, en especial con aquellas estrategias de planificación que involucren prácticas de treaty shopping, en la medida en que, debido a su generalidad, permite incluir dentro de su ámbito de aplicación un gran número de situaciones que pueden resultar abusivas.

Así las cosas, en aras de mitigar los efectos económicos no deseados que puedan generarse a causa del grado de incertidumbre que de por sí conlleva la aplicación de la PPT, 
es necesario establecer criterios objetivos que permitan decantar ciertas reglas tendientes a reducir el grado de subjetividad presente al momento de la aplicación de dicha cláusula, lo cual irá sucediendo, entre otras cosas, a través de la jurisprudencia de los tribunales y la doctrina nacionales y, en un futuro, los tribunales de arbitraje ante los que las partes sometan sus controversias.

2. La inclusión de la cláusula PPT no presenta inconvenientes en la red de Convenios suscritos por Colombia. Sin embargo, es necesario tomar en consideración que las posiciones adoptadas por cada Estado signatario respecto de la aplicación del MLi deberán ser tenidas en cuenta en el momento de aplicar los CDI cubiertos.

Lo anterior implica que, en la aplicación e interpretación de las disposiciones de un CDI, se deberá recurrir al texto del tratado y a los documentos de ratificación del Instrumento Multilateral de cada Estado contratante, lo cual causará que la aplicación de los Convenios para evitar la Doble Imposición sea más complicada tanto para los contribuyentes como para las autoridades tributarias.

En ese orden de ideas, en aras de facilitar la aplicación de los CDI con las modificaciones realizadas por el MLI, resulta recomendable la publicación de textos consolidados de los tratados de manera que, en la aplicación del convenio, solo se deba recurrir a un documento: en efecto, jurisdicciones como Alemania han anunciado su intención de publicar textos consolidados de sus CDI, que incluyan las modificaciones del MLI.

Así las cosas, la publicación de textos consolidados no solo facilitaría la consulta de los tratados, sino que, también, daría una mayor claridad a la hora de su aplicación reduciendo de esa manera el grado de incertidumbre que genera la aplicación de algunas disposiciones como la PPT.

Ahora bien, respecto de los convenios en los que se pretenda aplicar las recomendaciones del Plan de Acción para cumplir con el estándar mínimo propuesto por la oCDE, pero que no sean incluidos dentro de lo ámbito de aplicación del MLi por alguno de los Estados contratantes, se deberá adelantar una negociación directa encaminada a la implementación de dichas medidas pues, al no tener la calidad de convenio comprendido, el MLi no será aplicable a esos convenios como sucede, por ejemplo, con el cDi Colombia-Suiza; más aun teniendo en cuenta que ambos Estados, como miembros de la oCDE, están en la obligación de implementar los estándares fijados por esa organización a través del Plan de Acción BEPS pues, tal y como se mencionó anteriormente, al ser reconocidas y aplicadas por un número considerable de Estados que reconocen dichas recomendaciones como prácticas necesarias y obligatorias en materia de tributación internacional, las recomendaciones de la OCDE terminan adquiriendo cierta fuerza vinculante, toda vez que su inobservancia podría conllevar el uso eventual de contra medidas por parte de la oCDE o de los demás Estados miembros.

En ese orden de ideas, resulta indispensable que dicha negociación se adelante en condiciones reales y efectivas de reciprocidad que, además de garantizar la aplicación de las recomendaciones y estándares del Plan de Acción, proteja los intereses de ambos Estados, pues, siguiendo lo dispuesto por la Corte Constitucional Colombiana en sentencia 
C-460 de 2010, “debe examinarse, en cada caso particular, si los niveles de inversión y las políticas fiscales de cada uno de los Estados contratantes permiten garantizar un nivel de reciprocidad real y efectiva a través del convenio de doble imposición”.

\section{Referencias}

Báez Moreno, A. (2016). La cláusula del propósito principal (principal purpose test). Un análisis crítico de la Acción 6 del proyecto BEPs. Revista De Contabilidad y Tributación, (404), 5-52.

Bammens, N. \& De Broe, L. (2010). Treaty shopping and avoidance of abuse. In M. Lang, P. Pistone, J. Schuch, C. Staringer, A. Storck \& M. Zagler (Eds.), Tax treaties: Building bridges between law and economics (pp. 51-72). Amsterdam: IBFD.

Beltrán Losada, J. (2011). El fraude a la ley y la elusión fiscal: ¿buscan amparo en la planeación tributaria? Revista Impuestos, (167), 19-25.

Brauner, Y. (2014). What the BEPs? Florida Tax Review, 16(2), 55-115.

Calderón Carrero, J. M. y Quintas Seara, A. (2016a). Una aproximación al concepto de "planificación fiscal agresiva" utilizado en los trabajos de la oCDE (primera parte). Revista Análisis Tributario, (337), 14-24.

Chand, V. (2018). The principal purpose test in the multilateral convention: An in-depth analysis. Intertax, 46(1), 18-44. Retrieved from http://www.kluwerlawonline.com/ abstract.php?area=Journals\&id=TAXI2018004

Congreso de Colombia (31 de julio de 2009). Ley aprobatoria del Convenio entre la República de Colombia y la Confederación Suiza para Evitar la Doble Imposición en Materia de Impuestos sobre la Renta y Sobre el Patrimonio [Ley 1344 de 2009]. D.O.: 47.427

Congreso de Colombia (29 de junio de 2011). Ley aprobatoria del Convenio entre Canadá y la República de Colombia para evitar la doble imposición y para prevenir la evasión fiscal en relación con el impuesto sobre la renta y sobre el patrimonio [Ley 1459 de 2011]. D.O.: 48.116

Congreso de Colombia (16 de julio de 2013). Ley aprobatoria del Convenio entre la República de Corea y la República de Colombia para evitar la doble imposición y para prevenir la evasión fiscal en relación al impuesto sobre la renta [Ley 1667 de 2013]. D.O.: 48.853 
Congreso de Colombia (16 de julio de 2013). Ley aprobatoria del Acuerdo entre el Gobierno de la República de Colombia y la República de la India para evitar la doble imposición y prevenir la evasión fiscal en relación con el impuesto sobre la renta [Ley 1668 de 2013]. D.O.: 48.853.

Congreso de Colombia (17 de diciembre de 2013). Ley aprobatoria del Convenio entre la República Portugesa y la República de Colombia para evitar la doble imposición y para prevenir la evasión fiscal en relación con el impuesto sobre la Renta [Ley 1692 de 2013] D.O.: 49.007.

Falcón y Tella, R. y Pulido Guerra, E. (2010a). Planificación fiscal internacional y medidas antielusión. Derecho fiscal internacional. Madrid: Marcial Pons.

Girón Uribe, P.A. (2018). La conversión del soft law de la oCDE en hard law en Colombia, especial referencia a los Convenios para evitar la Doble Imposición suscritos por Colombia con Francia y Reino Unido. Revista de Derecho Fiscal, (12), 69-120.

Gómez Cifuentes, S. E. (2018). El test de propósito principal: de la incertidumbre a la seguridad jurídica. Revista Impuestos, (205), 19-27.

Hernández González-Barreda, P. A. (2017b). El alcance material y formal del plan BEPS: viejos conocidos, nuevos amigos y la necesidad de un nuevo enfoque. In J. M. Almudi Cid, J. A. Ferreras Gutiérrez \& P. A. Hernández González-Barreda (Eds.), El plan de acción sobre erosión de bases imponibles y traslado de beneficios (BEPS): G-20, ocDE y Unión Europea (pp. 37-65). Navarra: Thomson Reuters, Aranzadi.

HMRC (2015). Improving large business tax compliance. Consultation document.

Kuzniacki, B. (2018). The principal purpose test (PPT) in BEPS action 6 and the MLI: Exploring challenges arising from its legal implementation and practical application. World Tax Journal, 10(2), 233-294.

Lang, M. (2014, May 19,). BePs action 6: Introducing an antiabuse rule in tax treaties. Tax Notes International, 74, 655-664.

Marín Benítez, G. (2013). ¿Es lícita la planificación fiscal? Sobre los defectos de neutralidad y consistencia del ordenamiento tributario (1st ed.) Thomson Reuters.

Marín Benítez, G. (2017). El concepto de planificación fiscal agresiva en BEPs: una visión comparada con los conceptos de abuso de derecho de la unión europea y derecho español. In J. M. Cid Almudi, J. A. Ferreras Gutíerrez \& P. A. Hernández 
González-Barreda (Eds.), El plan de acción sobre erosión de bases imponibles y traslado de beneficios (BEPS): G-20, oCDE y Unión Europea (pp. 85-107). Navarra: Thomson Reuters, Aranzadi.

Merino Jara, I. (2014). Acerca del soft law en materia tributaria. Revista Instituto Colombiano de Derecho Tributario, (71), 17-46.

Mosquera Valderrama, I. J. (2015). The OECD-BEPS measures to deal with aggressive tax planning in south america and sub-saharan africa: The challenges ahead. Inter$\operatorname{tax}, 43(10), 615-627$.

oCDE (2013). Action plan on base erosion and profit shifting. París: OECD Publishing.

OCDE (2015). Measuring and monitoring BEPS, action 11-2015 final report. París: OECD Publishing.

OCDE (2016a). Desarrollar un instrumento multilateral que modifique los convenios fiscales bilaterales, Acción 15-informe final 2015. París: Éditions OCDE.

OCDE (2016b). Impedir la utilización abusiva de convenios fiscales, Acción 6-informe final 2015. París: Éditions OCDE.

Ramos Ángeles, J. A. (2015). El proyecto BEPs de la OCDE y el mito del fin de la planificación fiscal internacional: un enfoque crítico a propósito de los final reports 2015. Revista Derecho \& Sociedad, 45, 375-396.

Rozo Gutiérrez, C. (2016). Acción 6: El abuso de los tratados para evitar la doble tributación: ¿cómo delimitar la frontera con la planeación fiscal legítima? In D. A. Moreno Daza (Ed.), Resultados del plan de acción BEPS y su aplicación en Colombia (pp. 125-148). Bogotá D.C.: Instituto Colombiano de Derecho Tributario.

Sánchez-Archidona Hidalgo, G. (2017). La delimitación conceptual de la erosión de las bases imponibles: un problema internacional. Nueva Fiscalidad, (2), 139-158.

Sanín Gómez, J. E. (2015). Tributación de la economía digital; perspectivas desde el Derecho internacional. Revista Instituto Colombiano de Derecho Tributario, (72), 233-248.

Del Toro Huerta, Mauricio Iván (2006). El fenómeno del soft law y las nuevas perspectivas del Derecho internacional. Anuario Mexicano de Derecho Internacional, 6, 513-549. 
Van den Hurk, H. (2014). Starbucks versus the people. Bulletin for International Taxation, $68(1), 27$.

Vives Ruíz, F. (2013). Seguridad jurídica y desarrollo económico. España: Crecer en la nueva economía global (pp. 75-89). Madrid: Fundación de Estudios Financieros.

Zornoza Pérez, J. (2017). El convenio multilateral: un análisis preliminar. en J. M. Almudi Cid, J. A. Ferreras Gutiérrez y P. A. Hernández González-Barreda (Eds.), El plan de acción sobre erosión de bases imponibles y traslado de beneficios (BEPS): G-20, oCDE y Unión Europea (pp. 475-512). Madrid: Thomson Reuters. Aranzadi. 